\title{
Effects of plant community history, soil legacy and plant diversity on soil microbial communities
}

\author{
Marc W. Schmid ${ }^{1,2}$ (D) | Sofia J. van Moorsel ${ }^{1}$ (D) | Terhi Hahl ${ }^{1}$ | Enrica De Luca ${ }^{1}$ | \\ Gerlinde B. De Deyn ${ }^{3}$ \\ Cameron Wagg ${ }^{1,4}$ (i) \\ Pascal A. Niklaus ${ }^{1}$ \\ Bernhard Schmid ${ }^{1,5,6}$
}

\begin{abstract}
${ }^{1}$ Department of Evolutionary Biology and Environmental Studies, University of Zürich, Zürich, Switzerland; ${ }^{2}$ MWSchmid GmbH, Zürich, Switzerland; ${ }^{3}$ Soil Biology Group, Wageningen University, Wageningen, Netherlands; ${ }^{4}$ Agriculture and Agri-Food Canada, Fredericton, NB, Canada; ${ }^{5}$ Department of Geography, Remote Sensing Laboratories, University of Zürich, Zürich, Switzerland and ${ }^{6}$ Institute of Ecology, College of Urban and Environmental Sciences, Peking University, Beijing, China
\end{abstract}

\author{
Correspondence \\ Marc W. Schmid \\ Email: contact@mwschmid.ch

\section{Funding information} \\ Schweizerischer Nationalfonds zur \\ Förderung der Wissenschaftlichen \\ Forschung, Grant/Award Number: \\ 147092 and 166457; Deutsche \\ Forschungsgemeinschaft, Grant/Award \\ Number: FOR1451
}

Handling Editor: Manuel Delgado-Baquerizo

\begin{abstract}
1. Plant and soil microbial diversities are linked through a range of interactions, including the exchange of carbon and nutrients but also herbivory and pathogenic effects. Over time, associations between plant communities and their soil microbiota may strengthen and become more specific, resulting in stronger associations between plant and soil microbial diversity.
\end{abstract}

2. We tested this hypothesis at the end of a 4-year field experiment in 48 plots with different plant species compositions established 13 years earlier in a biodiversity experiment in Jena, Germany. We factorially crossed plant community history (old vs. new plant communities) and soil legacy (old vs. new soil) with plant diversity (species richness levels 1, 2, 4 and 8, each with 12 different species compositions). We use the term 'plant community history' to refer to the co-occurrence history of plants in different species compositions in the Jena Experiment. We determined soil bacterial and fungal community composition in terms of operational taxonomic units (OTUs) using 16S rRNA gene and ITS DNA sequencing.

3. Plant community history (old plants) did not affect overall soil community composition but differentially affected bacterial richness and abundances of specific bacterial taxa in association with specific plant species compositions. Soil legacy (old soil) markedly increased soil bacterial richness and evenness and decreased fungal evenness. Soil fungal richness increased with plant species richness, regardless of plant community history or soil legacy, with the strongest difference between plant monocultures and mixtures. Specific plant species compositions and functional groups were associated with specific bacterial and fungal community 
compositions. Grasses increased fungal richness and evenness and legumes decreased fungal evenness, but bacterial diversity was not affected.

4. Synthesis. Our findings indicate that as experimental ecosystems varying in plant diversity develop over time (2002-2010), plant species associate with specific soil microbial taxa. This can have long-lasting effects on below-ground community composition in re-assembled plant communities, as reflected in strong soil legacy signals still visible after 4 years (2011-2015). Effects of plant community history on soil communities are subtle and may take longer to fully develop.

\section{KEYWORDS}

16S-rRNA and ITS gene sequencing, biodiversity experiment, grassland, microbial C and N, N mineralization, soil bacteria, soil fungi, soil microbiome

\section{1 | INTRODUCTION}

Soil biota are critical drivers of soil processes such as nutrient cycling, thereby supporting primary productivity and plant diversity (Haines-Young \& Potschin, 2010; van der Heijden et al., 2008; Wagg et al., 2019). Soil microbial communities interact with plants in the plant rhizosphere as plants grow, and, more indirectly, via plant litter, which provides habitat and resources for a vast diversity of soil organisms. Plant-soil interactions can be positive or negative for plant growth but, more importantly, are dynamic and may take time to develop (Kardol et al., 2013; Lau \& Lennon, 2011, 2012; terHorst et al., 2014). Knowing how soil microbial communities co-assemble with plant communities over time and how plant diversity loss influences this co-assembly is crucial for understanding how above- and below-ground biodiversity affect ecosystem processes (Bardgett \& van der Putten, 2014; Wardle et al., 2004).

When plant biodiversity decreases (Schweitzer et al., 2014), microbial communities may change in abundance distributions or by evolution of taxa contained within them. Such altered microbial community compositions can in turn modify the composition and productivity of plant communities (Bartelt-Ryser et al., 2005; Kardol et al., 2007; Klironomos, 2002; Petermann et al., 2008; van der Putten et al., 2013). Plant-soil feedbacks can drive co-adaptation (Lau \& Lennon, 2011; Schweitzer et al., 2014; Wagg et al., 2014) and may incur selection for plant individuals able to reduce antagonistic and improve beneficial associations with soil organisms (van der Putten et al., 2013; Wagg et al., 2014). The commonly negative plant-soil feedback (van der Putten et al., 2013) could, therefore, over time switch to positive effects of the soil microbial community on plant growth (Zuppinger-Dingley et al., 2016).

Interactions between plants and soil microbes in old communities can lead to more diverse soil bacterial and fungal communities, as the co-occurrence allows for the development of more specific associations between plants and soil microbes (Gravel et al., 2011; Lau \& Lennon, 2011). This could be due to both plant community history, for example, through an increased niche separation between plants with a co-occurrence history (Zuppinger-Dingley et al., 2014), or to soil legacy (Bartelt-Ryser et al., 2005). Bacterial and fungal diversity have been shown to increase along a gradient of plant diversity (Lange et al., 2015), because there are more plant species to be associated with. Thus, plant species richness may influence how plant community history and soil legacy shape microbial communities. Assuming a strong plant host effect, increasing the number of plant host species should also increase the number of microbial species. Previously, it was shown that individual plant species can select for a suite of microbes (Bezemer et al., 2010; Schmid et al., 2019). In extension, each plant community composition, for example, containing a specific plant functional group or plant species could assemble its own specific microbial community, which we aimed to test here.

Our study was in part motivated by two previous studies from the Jena Experiment where our experiment was also conducted. The first showed positive relationships between plant diversity and bacterial and fungal diversity (Lange et al., 2015), whereas a later study found a positive relationship only for fungal diversity and an overruling impact of soil abiotic variables and plant functional group identity on bacterial and fungal community composition (Dassen et al., 2017). These contrasting results from the same biodiversity experiment at two different time points again suggest that relationships may change over time (yet may also depend on the methodology used, that is, T-RFLP vs. Illumina sequencing of $16 \mathrm{~S}$ and $18 \mathrm{~S}$ rRNA gene fragments). Therefore, we wanted to test how co-evolution between plant and soil communities, that is, plant community history and soil legacy ('age'), may affect the diversity and composition of soil bacterial and fungal communities. In addition, we asked whether plant diversity modifies the effects of plant community history and soil legacy. During these 8 years, plant communities may have developed associations with a specific suite of soil microbes (Schmid et al., 2019). We, therefore, use the term 'soil legacy' to refer to soil communities that developed under these plant communities.

In a new field experiment we re-created the same plant species compositions as those used in the 'training' phase (being the Jena field experiment) and planted them adjacent to those old communities. We factorially combined plant and soil communities with or without plant community history and soil legacy, respectively. The 
different combinations of plant community history (old vs. new plant communities) by soil legacy (old vs. new soil), for each plant species composition, were grown for 4 years as re-assembled communities (Figure 1). At harvest, we took soil samples and assessed microbial diversity and composition.

\section{2 | MATERIALS AND METHODS}

\section{1 | Study site and experimental design}

The experiment was carried out at the Jena Experiment field site

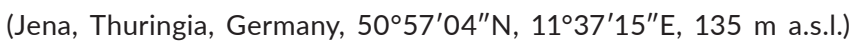
from 2011 to 2015. The Jena Experiment is a long-term biodiversity experiment in which 60 grassland species have been grown in different combinations since 2002 (Roscher et al., 2004; Weisser et al., 2017). This study was conducted in experimental plots established within the larger plots of the Jena Experiment (van Moorsel et al., 2018).

We used a split-split plot design with the three factorially crossed treatments (Figure 1) plant species richness (1, 2, 4, 8, 60 species), soil legacy (soil from the original field plot unsterilized or sterilized and inoculated with the same soil or with neutral soil) and plant community history (old vs. new). Plant species richness and composition were manipulated at plot level. For the four richness levels 1, 2, 4 and 8 there were 12 different species compositions each, serving as replicates to test richness effects; and the plant species belonged to four plant functional groups (legumes, grasses and tall and short herbs; Roscher et al., 2004). There were also four replicates of the full 60-species mixture containing all species used in the experiment. Soil legacy was manipulated at the split-plot level and plant community history at the split-split-plot level. Some treatment

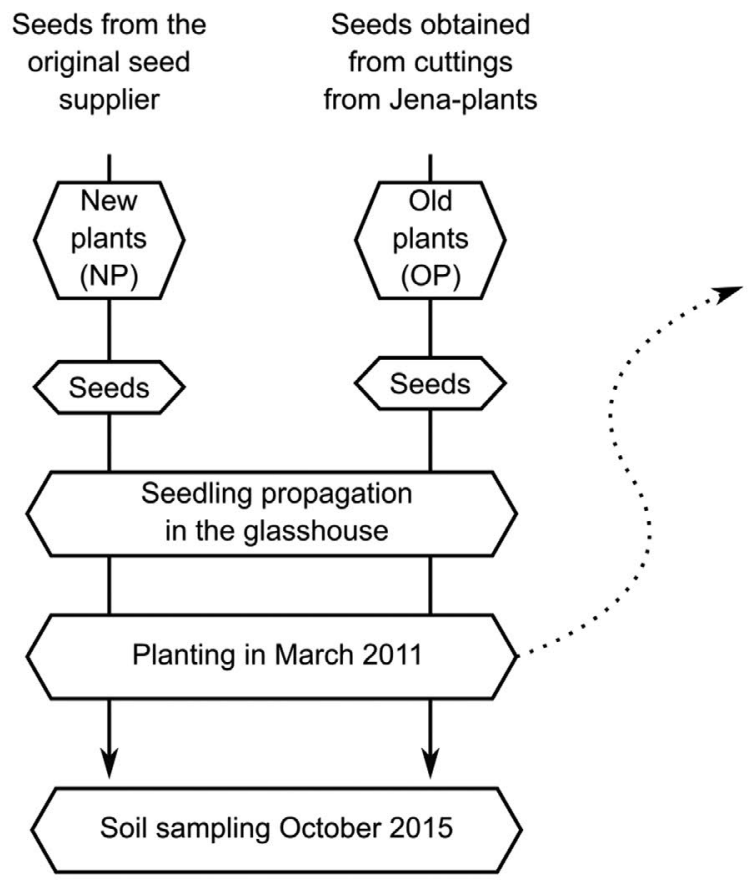

Plot from field plot in Jena $(2 \times 2 \mathrm{~m})$
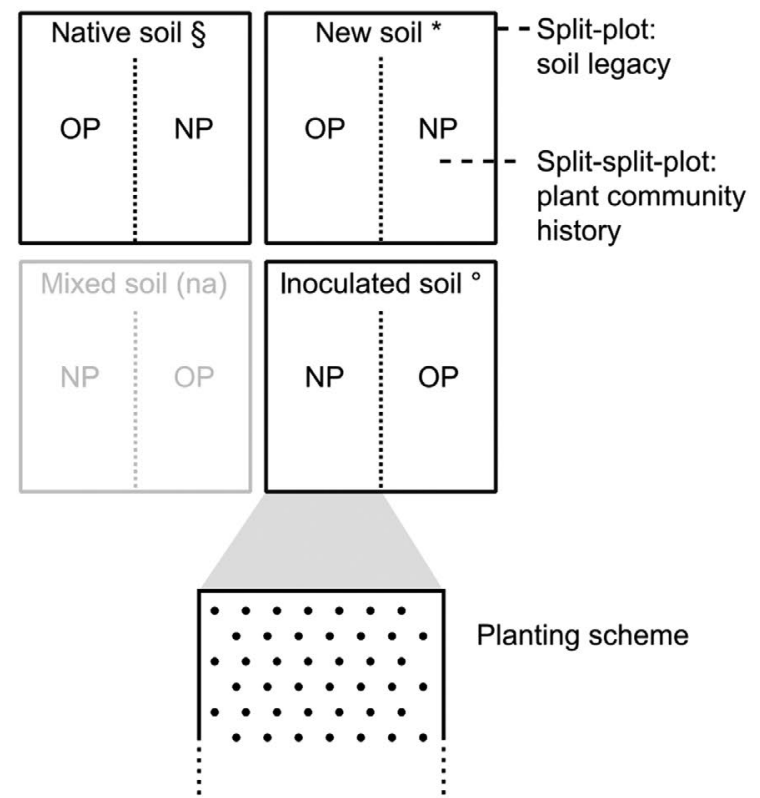

\begin{tabular}{|c|c|c|c|c|c|c|c|}
\hline \multicolumn{2}{|c|}{$\begin{array}{l}\text { Soil legacy (SL) } \\
\text { Community hist. }(\mathrm{CH})\end{array}$} & \multicolumn{2}{|c|}{ New soil * } & \multicolumn{2}{|c|}{ Inoculated old soil ${ }^{\circ}$} & \multicolumn{2}{|c|}{ Native old soil § } \\
\hline \multirow{3}{*}{$\begin{array}{c}\text { Plant } \\
\text { species } \\
\text { richness } \\
(\mathrm{SR})\end{array}$} & 1 & $11 / 10$ & 11 & 11 & 11 & 11 & 12 \\
\hline & 4 & $11 / 10$ & 12 & 12 & 12 & 11 & 12 \\
\hline & 8 & 12 & 12 & 12 & 11 & 12 & 12 \\
\hline
\end{tabular}

* New soil: sterilized soil $+4 \%$ sugar beet soil

- Inoculated old soil: sterilized soil $+4 \%$ sugar beet soil $+4 \%$ native soil $\S$ Native old soil: untreated soil

NP: no co-selection, planted in identical composition OP: co-selected plants, grown in Jena Field Experiment since 2002

FIGURE 1 Schematic of the experimental design. Plants with a history of growing in the Jena Experiment for 8 years in their respective communities (old plant communities) were planted in communities next to identical communities consisting of plants without such a history (new plant communities). After planting, the communities were monitored for 4 years after which the soil samples for this study were collected, so that the 'old' plant communities on 'old' soil had an interaction with their local soil for 12 years and the new plant communities only for 4 years. Numbers in the table are replicate communities. One split-plot with mixed soil was destructively harvested for a different experiment and is therefore not included in this paper 
combinations had missing replicates because they included a wrong plant species (van Moorsel et al., 2018) or DNA extraction from soil samples failed (Figure 1). At the 60-species plant richness level, we only tested new communities without plant community history and without soil legacy, therefore this richness level was only included in some of the analyses.

\section{2 | Soil legacy treatments}

In 2010, 8 years after the beginning of the Jena Experiment, we established the plots used in this study within the larger experimental plots of the Jena Experiment. Each plot contained four $1 \mathrm{~m}^{2}$ quadrats (split-plots) with different soil treatments in each. One quadrat was used for a different experiment and is therefore not included in this study. To create the soil treatments, within each of these $2 \times 2 \mathrm{~m}$ plots, we removed the original plant cover in September 2010, excavated the $0-35-\mathrm{cm}$ topsoil and sieved the soil (2 cm mesh). To minimize the exchange of soil components between the four $1-\mathrm{m}^{2}$ quadrats and the surrounding soil, we separated the quadrats with plastic frames. Two $5-\mathrm{cm}$ layers of sand, separated by a $0.5-\mathrm{mm}$ mesh, were added to the bottom.

Half of the excavated soil was directly filled back into the plots to create a 'native old' soil treatment and a treatment not used for the present experiment. The other half of the excavated soil (around $600 \mathrm{~kg}$ per plot) was gamma-sterilized with a dose of $50 \mathrm{kGy}$ to kill soil biota (McNamara et al., 2003). Half of this sterilized soil was then inoculated with $4 \%$ (by weight) of sugar beet soil and $4 \%$ of sterilized soil to create a 'new' soil treatment. The other half of the sterilized soil was inoculated with $4 \%$ of sugar beet soil and $4 \%$ of unsterilized soil as used for the native old treatment to create a second old soil treatment that we termed 'native inoculated'. We used these small inoculum volumes to minimize potential abiotic feedback effects of the inocula (Brinkman et al., 2010). Similar amounts of soil inoculum had produced significant soil-legacy effects in previous experiments (Bartelt-Ryser et al., 2005; Dudenhöffer et al., 2018). Sugar beet soil was added to create a natural soil community also for the new soil treatment. This soil was collected in a near sugar beet field not associated with the Jena Experiment, but with comparable soil abiotic properties. Soil legacy thus comprised three soil treatments: native old soil, native inoculated soil and new soil. The contrast old versus new soil compared the first two legacy treatments with the third.

\subsection{Plant species richness and plant community history treatments}

We used two plant community history treatments: 'old plant communities' (with 8 years of co-occurrence history in the Jena Experiment) versus 'new plant communities' (plant communities established from plants without such co-occurrence history). Seeds for the new communities were obtained from the original seed supplier of the Jena Experiment (Rieger Hofmann GmbH, in Blaufelden-Raboldshausen,
Germany). To produce seeds for the old communities, cuttings made after 8 years (2010) in the Jena Experiment were transferred and planted in the original species combination in plots of an experimental garden in Zurich, Switzerland. Plots were surrounded by nets to reduce pollination between communities and only left open on top to allow pollinator access (Zuppinger-Dingley et al., 2014). Seeds for the old communities were thus offspring of plant populations that had been sown in 2002 and grown until 2010 in plots of the Jena Experiment.

To remove potential maternal effects, all seeds were germinated in potting soil (BF4, De Baat, The Netherlands) in midJanuary 2011 in a glasshouse in Zurich. In March 2011, the seedlings were transferred to the field site of the Jena Experiment and planted within the $2 \times 2 \mathrm{~m}$ plots. Each $1 \times 1 \mathrm{~m}$ quadrat (splitplot) was further divided into two equally sized halves (splitsplit-plots, Figure 1). The seedlings of old communities were transplanted into one half and seedlings of new communities into the other half of each quadrat at a density of 210 plants $/ \mathrm{m}^{2}$. Species were planted in equal proportions with a total of 105 individuals per split-split-plot. Species that in 2010 were no longer present in an original plot were excluded from all planted communities in the subplots of that plot (five out of all 60 plant species were completely excluded because they had gone extinct in all sampled communities in which they had originally been planted in the Jena Experiment). The plant communities were grown from 2011 to 2015 and maintained by weeding three times a year and by cutting twice a year in late May and August, which are typical grassland harvest times in central Europe.

\subsection{Soil sampling and soil microbial biomass and activity}

Once the old and new plant communities and their associated soil microbial communities had been allowed to develop for 4 years, soil samples were collected (early October 2015) in each of the six split-split-plots (two in case of the 60-species mixtures). Several soil samples from the top 5-10 cm of soil depth were collected per splitsplit-plot and pooled. This yielded a total of (6 split-split-plots $\times 4$ species richness levels $\times 12$ species compositions $)+(2$ split-splitplots $\times 4$ 60-species mixtures) -9 missing replicates $=287$ splitsplit-plots or samples (Figure 1). Soil samples were then sieved to $2 \mathrm{~mm}$ and divided into two sub-samples of which one was used for soil chemical analysis and the other one for DNA extraction and subsequent 16S/ITS sequencing. For the DNA extraction, we weighed approximately $0.5 \mathrm{~g}$ of fresh soil per sample, added buffer and froze the samples at $-80^{\circ} \mathrm{C}$.

Gravimetric soil water content was determined by oven-drying $\left(105^{\circ} \mathrm{C}\right.$ for $\left.24 \mathrm{hr}\right)$. Soil microbial carbon and nitrogen were determined by chloroform-fumigation extraction (Brookes et al., 1985; Vance et al., 1987). In brief, $10 \mathrm{~g}$ of soil were extracted with $25 \mathrm{ml}$ $0.5 \mathrm{M} \mathrm{K}_{2} \mathrm{SO}_{4}$ (45 min, $150 \mathrm{rpm}$ ), the suspension filtered (MN 615, Macherey-Nagel AG) and dissolved organic carbon and nitrogen 
in the filtrate quantified with a TOC analyser (Dimatoc 2000; Dimatec Analysentechnik $\mathrm{GmbH}$ ). A second sample was processed similarly after fumigation with ethanol-free chloroform. Microbial $\mathrm{C}$ and $\mathrm{N}$ were calculated assuming an extraction efficiency of $k_{\mathrm{EC}}$ $=0.45$ (Vance et al., 1987) and $k_{\mathrm{EN}}=0.54$ (Brookes et al., 1985), respectively.

Potential nitrogen mineralization was determined in laboratory incubations under anaerobic conditions (Keeney, 1982). Soil samples (20 g fresh weight) were incubated for 7 days at $40^{\circ} \mathrm{C}$ in $30 \mathrm{ml}$ centrifuge tubes containing $20 \mathrm{ml}$ of extra water, leaving minimal headspace. After incubation, the tubes were vortexed, samples transferred to $100 \mathrm{ml}$ polypropylene cups and $40 \mathrm{ml}$ of $3 \mathrm{M} \mathrm{KCl}$ added, yielding a concentration of $2 \mathrm{M} \mathrm{KCl}$ in the suspension. The suspension was extracted on a table shaker for $30 \mathrm{~min}$. After sedimentation and filtration of the supernatant, the now soil-free extract was stored frozen $\left(-18^{\circ} \mathrm{C}\right)$ until determination of $\mathrm{NH}_{4}^{+}$concentrations (Skalar SAN+ segmented flow analyser, Skalar Analytical B.V.).

Available phosphorus was determined using the method of Olsen (Olsen et al., 1954). Two grams of fresh soil were extracted with $40 \mathrm{ml} 0.5 \mathrm{M} \mathrm{NaHCO}_{3}(\mathrm{pH} 8.5$, table shaker, $30 \mathrm{~min}$ ) and the supernatant filtered. Phosphate in the extract was determined colorimetrically using the molybdate blue method (Watanabe \& Olsen, 1965) on the same segmented flow analyser.

\section{5 | Bacterial 16S rDNA and fungal ITS sequencing}

We used Illumina sequencing markers of both bacteria and fungi (16S and ITS fragments, respectively) to determine the community structure and diversity of bacteria and fungi in bulk soil. Bacterial and fungal OTU richness, effective species richness and evenness as well as OTU abundances were used as target measures. In June 2016, DNA was isolated from 500 mg of bulk soil using the FastDNA SPIN Kit for Soil (MP Biomedicals, Illkirch-Graffenstaden, France) following the manufacturer's instructions. We used the primer pair ITS1-F_KYO2 (5'-TAGAGGAAGTAAAAGTCGTAA) and ITS2_KYO2 (5'-TTYRCTRCGTTCTTCATC) to amplify the internal transcribed spacer subregion 1 (ITS1, Toju et al., 2012) and the primer pair S-DBact-0341-b-S-17 (5'-CCTACGGGNGGCWGCAG) and S-D-Bact0785-a-A-21 (5'-GACTACHVGGGTATCTAATCC) to amplify the variable regions $\mathrm{V} 3$ and $\mathrm{V} 4$ of the prokaryotic ribosomal RNA gene (Herlemann et al., 2011). 16S/ITS specific sequences were fused to generic adapters (forward: 5'-ACACTGACGACATGGTTCTACA, reverse: 5'-TACGGTAGCAGAGACTTGGTCT) for the first round of PCR. The PCR conditions for the amplification of the $16 \mathrm{~S}$ and ITS regions consisted of an initial denaturation at $94^{\circ} \mathrm{C}$ for $15 \mathrm{~min}$, 30 cycles of denaturation at $94^{\circ} \mathrm{C}$ for $40 \mathrm{~s}$, an annealing at $58^{\circ} \mathrm{C}$ for $40 \mathrm{~s}$, and an elongation at $72^{\circ} \mathrm{C}$ for 1 min followed by a final elongation at $72^{\circ} \mathrm{C}$ for $10 \mathrm{~min}$. The PCR products were purified according to the manufacturer's instructions (NucleoSpin Gel and PCR (lean-up) and amplicon concentrations were measured with Qubit (Tecan Spark M10 plate reader with Pico Green). All samples were diluted to a concentration of $0.5 \mathrm{ng} / \mu \mathrm{l}$ and shipped to
GenomeQuebec for library preparation and sequencing. Samples were paired-end sequenced $(2 \times 250 \mathrm{bp}$ ) on the Illumina HiSeq system (GenomeQuebec). Short-reads were deposited at SRA (accession number PRJNA639013).

\section{6 | Identification and annotation of OTUs}

Operational taxonomic units (OTUs) were generated with UPARSE (version 10.0.024, Edgar, 2013) following the example and the tutorial given for paired-end Illumina data (drive5.com/uparse/). Reads were first quality-checked with FastQC (bioinformatics. babraham.ac.uk/projects/fastqc). Following removal of adapter sequences and low-quality bases with Trimmomatic (version 0.33 with the parameters ILLUMINACLIP:adapterSeqs:2:30:10 SLIDINGWINDOW:5:15 MINLEN:100, Bolger et al., 2014), pairedend reads were merged using usearch (with the parameters fastq_maxdiffs 25 -fastq_maxdiffpct 10 for merging, Edgar, 2013). Bacterial and fungal sequences were split into separate files based on the primer sequences matching at both ends of the bacterial and fungal sequences using a custom python script. Matching primer sequences were removed during this process. Sequences without matches on both ends were discarded (3.2\%). Sequences were then quality filtered with usearch (with the parameter -fastq_maxee 1, Edgar, 2013) and duplicated sequences were collapsed with fqtrim (version 0.9.4, Pertea, 2015). For the fungal sequence data, the highly variable subregion ITS1 was extracted with ITSx (version 1.1.1, previously it was $1.1 \mathrm{~b}$, with the parameters - $t$ funghi -reset T -preserve T -save_regions ITS1, Bengtsson-Palme et al., 2013). Bacterial and fungal ITS1 sequences were then denoised with usearch (with the parameter -unoise3, Edgar, 2013). The fungal ITS1 data were filtered for chimeras using the UNITE 7 database (reference dataset for UCHIME, version 7.2, Nilsson et al., 2019) and usearch (with the parameters -uchime_ref -strand plus -mode balanced, Edgar, 2013). Remaining sequences were sorted according to their length (required for usearch -cluster_smallmem) and clustered with a minimal identity threshold of $99 \%$ using usearch (parameters -sortbylength -minseqlength 64 for sorting and -cluster_smallmem -id 0.99 for clustering, Edgar, 2013). The fungal ITS1 data were again filtered for chimeras using the UNITE7 database (reference dataset for UCHIME, version 7.2, Nilsson et al., 2019) and usearch (with the parameters -uchime_ref -strand plus -mode balanced, Edgar, 2013). Finally, we obtained 7,616 bacterial and 16,844 fungal OTU sequences (sequences are available on https://doi.org/10.5281/zenodo.4596692). For the fungal data, four samples were removed because they had $<50$ reads in total whereas all other samples had more than 10,500 reads.

OTU sequences were annotated with the taxonomy data available from the Ribosomal Database Project (bacterial sequences, version 16, Cole et al., 2014) and UNITE (reference dataset for UTAX, version 7.1, Nilsson et al., 2019) with usearch (version 10.0.240, with the parameters -sintax -strand both -sintax_cutoff 0.8, Edgar, 2016). Fungal ITS-OTUs were further annotated with functional categories 
using FUNGuild (version 1.1, Nguyen et al., 2016). OTU abundances were finally obtained by counting the number of sequences (merged and filtered) matching to the OTU sequences (version 10.0.024 with the parameters -usearch_global -strand plus -id 0.97, Edgar (2013), annotations are available on https://doi.org/10.5281/zenodo. 4596692). OTUs annotated as chloroplast were removed to avoid a potential bias caused by plant DNA (mitochondrial sequences were not present in the databases and therefore not removed). To avoid sequencing artifacts, OTU sequences with $<30$ counts in total or with counts in less than four samples were removed from all further analyses (14,469 bacterial and 5,214 fungal OTUs remained after this filter).

\subsection{1 | Data normalization and identification of differentially abundant OTUs}

Normalized OTU counts were calculated with DESeq2 and $\log 2(x+1)$-transformed to obtain approximately normally distributed OTU abundances. Sequencing data were not rarefied (McMurdie \& Holmes, 2014). Variation in relative abundances of individual OTUs was analysed using analysis of variance (ANOVA) and linear model functions in $\mathrm{R}$ ( $\mathrm{R}$ Development Core Team, 2017), but after excluding the plots with 60 plant species. For a given term in the model, $p$-values from all OTUs were adjusted for multiple testing (Benjamini \& Hochberg, 1995). OTUs with an adjusted $p$-value (false discovery rate, FDR) below 0.01 and explaining more than $1 \%$ of the variation in relative abundances of individual OTUs were considered to be differentially abundant.

Fungal and bacterial species richness was calculated as the number of detected OTUs per sample. Shannon diversity $(\mathrm{H})$ was calculated with the function diversity() from the VEGAN package (version 2.4-4, function rda(); Oksanen et al., 2017). Effective richness was calculated as $\exp (\mathrm{H})$ and Pielou's evenness was calculated as $(\mathrm{H} /$ In(species richness)).

\subsection{2 | Functional groups of differentially abundant fungal OTU}

To test for enrichment/depletion of fungal functional groups (e.g. guilds) in each set of OTUs (e.g. OTUs with significant difference in abundance between treatment levels), we constructed for each group a contingency table with the within/outside group counts for the given set of OTUs and all OTUs passing the filter. We then tested for significance with Fisher's exact test. $p$-values were adjusted for multiple testing (Benjamini \& Hochberg, 1995), and group with an adjusted $p$-value (false discovery rate, FDR) below 0.05 were considered significantly enriched/ depleted (Table S2). With enrichment/depletion of a certain group we refer to a significantly more/less frequent occurrence of the group in a set of OTUs compared with the group in the set of OTUs which were randomly sampled (i.e. expected number of OTUs of group $A=$ number of OTUs in a set $\times$ frequency of group $A$ in all identified OTUs).

\subsection{Assessment of microbial community structure}

Divergence in microbial community composition between all samples in relation to the environmental factors was visualized with a redundancy analysis (RDA). The RDA was conducted in $\mathrm{R}$ with the package VEGAN (version 2.4-4, function rda(); Oksanen et al., 2017). Input data were log-transformed and normalized OTU counts used as response variables. The treatment factors with all interactions were used as constraints for the RDA.

We analysed the variation in dissimilarities between microbiomes with a multivariate ANOVA in $\mathrm{R}$ with the package VEGAN (version 2.4-4, function adonis(); Oksanen et al., 2017). Because of the large number of OTUs involved, we used the Manhattan distance as a dissimilarity measure (Aggarwal et al., 2014). For the differences in phylogenetic composition of the bacterial communities we used a multivariate ANOVA with UniFrac distances (Lozupone et al., 2011).

\subsection{1 | ANOVA models}

The structure of all ANOVA models followed general design principles that have been applied in other biodiversity experiments (Schmid et al., 2002, 2017). For all models, factors were fitted sequentially (type I sum of squares) as shown in Table 1 and 2. Significance tests were based on $F$ tests using appropriate error terms and denominator degrees of freedom (Schmid et al., 2017). The fixed terms of the models were spatial variation across the field site (given the latitudinal $(x)$ and longitudinal $(y)$ coordinates of each plot, we made a combined term for spatial variation consisting of the five contrasts $x+y+x^{2}+y^{2}+x \times y$, a spatial response surface that had proven useful to correct of spatial variation among plots in a previous analysis (Le Roux et al., 2013)), plant species richness and plant species composition contrasts (comparing monocultures with mixtures, assessing log-linearized species richness (logSR) and comparing plots with legumes/grasses/herbs with others), soil legacy (composed of two contrasts, new vs. old followed by native vs. native inoculated within old), plant community history $(\mathrm{CH})$ and two- and three-way interactions between treatment terms. The random terms were plot and its two-way interaction with soil legacy (split-plots) and the three-way interaction with soil legacy and plant community history (split-split-plots).

A limitation of our study is that we could only assess microbial community composition at the end of the experiment, first because our split-split-plots were rather small to allow for repeated soil sampling and second because we lacked funding for multiple moleculargenetic analyses. Thus, we focused our analysis on testing effects of treatments that were randomized and replicated to avoid confounding with unmeasured environmental variables or heterogeneous baselines. Nevertheless, these influences likely increased error variation and thus may have prevented us from detecting more subtle treatment effects. 
TAB LE 1 Analysis of variance of bacterial (A) and fungal (B) richness (number of OTUs), effective richness (exp(H)) and Pielou's evenness. Significant $p$-values are highlighted in bold. is monoculture: a contrast to compare plant monocultures with plant species mixtures, logSR: log2 of plant species richness, hasGrass: contrast for presence/absence of grasses, AGE: new soil compared with the two other soils (native and native inoculated soils), INO: inoculated compared with native soil, $\mathrm{CH}$ : plant community history. $d f$ : degrees of freedom, $F$ : $F$-value, $p$ : $p$-value, \%-SS: percentage of total sum of squares (corresponding to increases in multiple $R^{2} \times 100$ with addition of the specific term to the model). Non-significant interaction terms ( $p \geq 0.05$ for all three variables) are not listed in the table

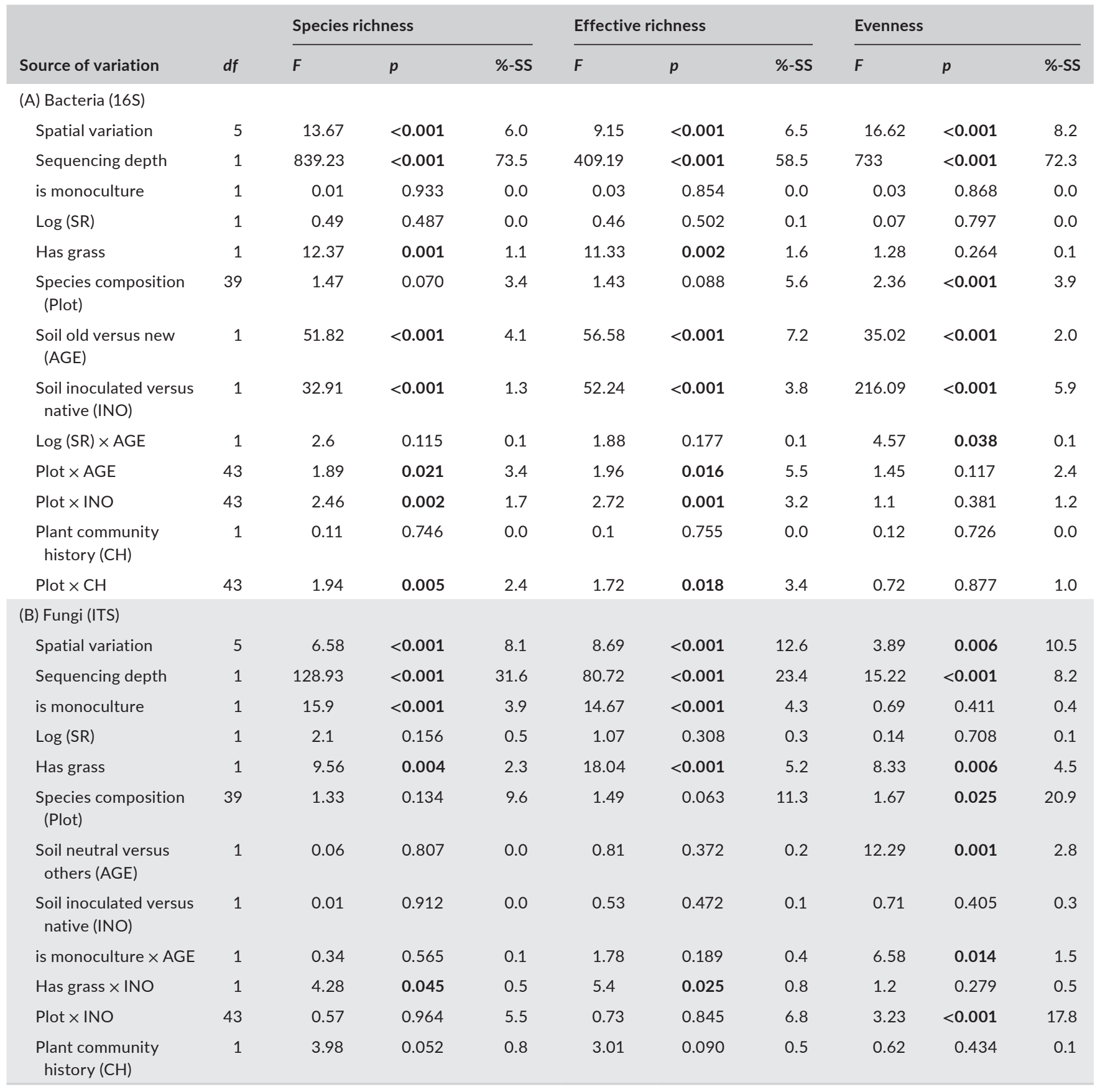

\subsection{2 | Mediator analysis}

To test whether the effect of the treatments was direct or indirect due to differences in soil chemistry, we used mediator analysis (Burns \& Brandt, 2014) as implemented in the package LAVAAN (Rosseel, 2012). To account for spatial variation of the soil chemistry in the field (Le Roux et al., 2013), we first fitted a model with the plot coordinates and used the residuals for further analyses. We tested the direct and indirect effects of soil legacy or plant species richness on microbial diversity measures in separate models. Plant community history had no significant effects and therefore this analysis is not presented. 
TABLE 2 Multivariate analysis of variance of dissimilarities (Manhattan distance) between bacterial (A) and fungal (B) community compositions. Significant $p$-values are highlighted in bold. is monoculture: a contrast to compare plant monocultures with plant species mixtures, logSR: log2 of plant species richness, hasGrass: contrast for presence/absence of grasses, AGE: new soil compared with the two other soils, INO: inoculated compared with native soil, $\mathrm{CH}$ : plant community history. $d f$ : degrees of freedom, $F$ : $F$-value, $p$ : $p$-value, \%-SS: percentage of total sum of squares (corresponding to increases in multiple $R^{2} \times 100$ with addition of the specific term to the model). Interaction terms are not listed in the table because none of them were significant

\begin{tabular}{|c|c|c|c|c|}
\hline \multirow[b]{2}{*}{ Source of variation } & \multirow[b]{2}{*}{$d f$} & \multicolumn{3}{|c|}{ Community composition } \\
\hline & & $F$ & $p$ & $\%$ SS \\
\hline \multicolumn{5}{|l|}{ (A) Bacteria (16S) } \\
\hline Spatial variation & 5 & 2.97 & 0.023 & 7.2 \\
\hline is monoculture & 1 & 1.44 & 0.237 & 0.7 \\
\hline $\log (S R)$ & 1 & 1.23 & 0.274 & 0.6 \\
\hline Has grass & 1 & 5.53 & 0.024 & 2.7 \\
\hline $\begin{array}{l}\text { Species composition } \\
\text { (Plot) }\end{array}$ & 39 & 1.76 & 0.016 & 18.8 \\
\hline $\begin{array}{l}\text { Soil new versus } \\
\text { others (AGE) }\end{array}$ & 1 & 26.9 & $<0.001$ & 7.3 \\
\hline $\begin{array}{l}\text { Soil inoculated } \\
\text { versus native (INO) }\end{array}$ & 1 & 24.7 & $<0.001$ & 6.9 \\
\hline $\begin{array}{l}\text { Plant community } \\
\text { history }(\mathrm{CH})\end{array}$ & 1 & 1.1 & 0.312 & 0.2 \\
\hline \multicolumn{5}{|l|}{ (B) Fungi (ITS) } \\
\hline Spatial variation & 5 & 2.21 & 0.073 & 7.2 \\
\hline is monoculture & 1 & 1.55 & 0.221 & 1.0 \\
\hline $\log (S R)$ & 1 & 1.58 & 0.216 & 1.0 \\
\hline Has grass & 1 & 9.44 & 0.004 & 6.2 \\
\hline $\begin{array}{l}\text { Species composition } \\
\text { (Plot) }\end{array}$ & 39 & 2.34 & $<0.001$ & 25.5 \\
\hline $\begin{array}{l}\text { Soil new versus } \\
\text { others (AGE) }\end{array}$ & 1 & 13.5 & $<0.001$ & 4.2 \\
\hline $\begin{array}{l}\text { Soil inoculated } \\
\text { versus native (INO) }\end{array}$ & 1 & 9.83 & 0.003 & 2.4 \\
\hline $\begin{array}{l}\text { Plant community } \\
\text { history }(\mathrm{CH})\end{array}$ & 1 & 1.08 & 0.304 & 0.2 \\
\hline
\end{tabular}

\section{3 | RESULTS}

\section{1 | Effects of soil legacy and plant species} richness, composition and community history on the diversity of soil bacterial and fungal communities

Of 14,469 16S-OTUs, 11,672 were classified as bacteria (including 8 OTUs of Archaea) and 2,797 remained unknown. Of the 5,214 ITSOTUs, 2,258 were classified as fungi and 2,956 remained unknown. The first two RDA axes explained $19.4 \%$ and $6.4 \%$ of the total variation in bacterial and fungal OTUs, respectively (Figure 2). The first axis separated the bacterial and fungal communities according to soil-legacy and the second axis according to plant species richness.

Bacterial effective OTU richness and evenness were highest in the native old soil and lowest in the new soil (Table 1; Figure 3). Furthermore, bacterial OTU richness was higher when plant species compositions contained grasses (irrespective of the identity of other plant functional groups present) than when they did not. Bacterial richness and evenness varied significantly among the different plant species compositions (plots, after correction for spatial covariates) within plant diversity levels (note that plant diversity terms were tested against this variation among species compositions, Schmid et al., 2017). Bacterial richness was also affected by a significant interaction between plant species composition and plant community history ('Plot $\times \mathrm{CH}^{\prime}$ interaction in Table 1).

In contrast to bacteria, fungal richness was not affected, and fungal evenness was reduced by soil legacy (Table 1; Figure 3). Also, in contrast to bacteria, fungal species richness and effective species richness were larger in plant mixtures than in plant monocultures. The presence of grasses in plant communities significantly increased all three indices of fungal diversity (Table 1), whereas the presence of legumes significantly decreased effective fungal evenness (Table S1). Fungal evenness varied significantly among plant species compositions within plant diversity levels, but without interaction with plant community history.

\subsection{Effects of soil legacy and plant species richness, composition and community history on the composition of soil bacterial and fungal communities}

In addition to the RDA analysis presented at the beginning of this Results section, we used multivariate ANOVAs to test treatment effects on bacterial and fungal community compositions. The overall pattern of significances was similar for the two groups of microbes (Table 2, Table S2 using phylogenetic community composition). There were clear effects of soil legacy, the presence of grasses and large variation among plant species composition within plant diversity levels. Furthermore, the presence of legumes significantly affected fungal community composition ( $p=0.015$ and $p=0.033$, respectively, for legume instead of grass contrasts in multivariate ANOVAs with or without phylogenetic community composition).

Because the multivariate analyses could only detect whether compositions of bacterial or fungal communities overall differed between treatments, but not how they differed, we additionally tested each 16S-/ITS-OTU for differential abundance with the models used for the biodiversity indices and community composition (Table 3). Of the 11,883 and 4,219 16S- and ITS-OTUs tested, 7,804 (65.6\%) and $2,489(59.0 \%)$ showed one or several significant treatment effects. For both bacterial (16S) and fungal (ITS) OTUs soil legacy (Figure 4), plant species composition (plot after correction for spatial covariates) and their interaction were often significant (Table 3). Among the different plant species compositions, especially those containing grasses or legumes clearly had different patterns of OTU abundances 
FIGURE 2 Redundancy analysis (RDA) using the normalized operational taxonomic unit (OTU) abundances of all samples analysed. For the bacterial 16S-OTUs (left) the first two RDA axes explained $19.4 \%$ of the variance (all RDA axes together: $24.7 \%)$. For the fungal ITSOTUs (right) the first two axes explained $6.4 \%$ of the variance (all RDA axes together: $13.1 \%)$. In the upper two panels, points indicate different soil legacy and plant community history and in the lower two panels, points indicate different plant species richness (darker purple higher richness)

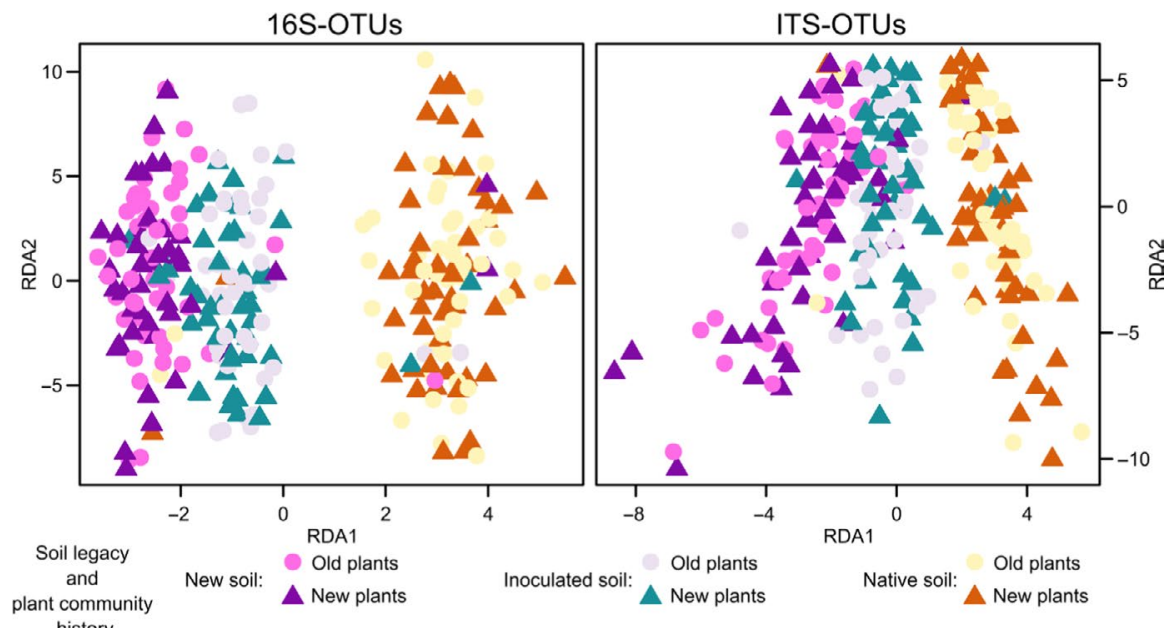

16S-OTUs

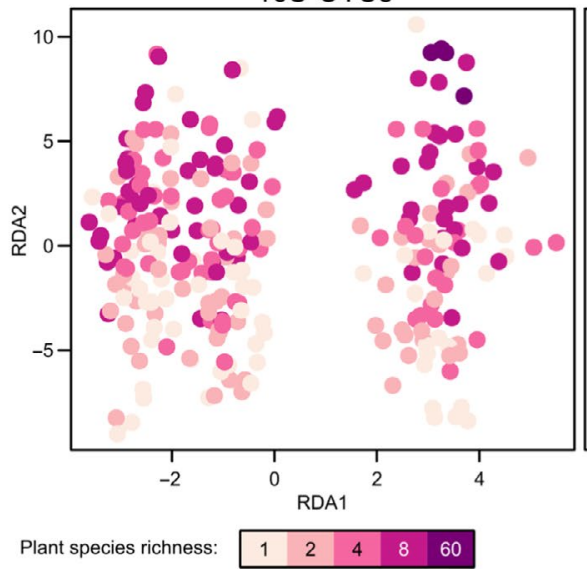

ITS-OTUS

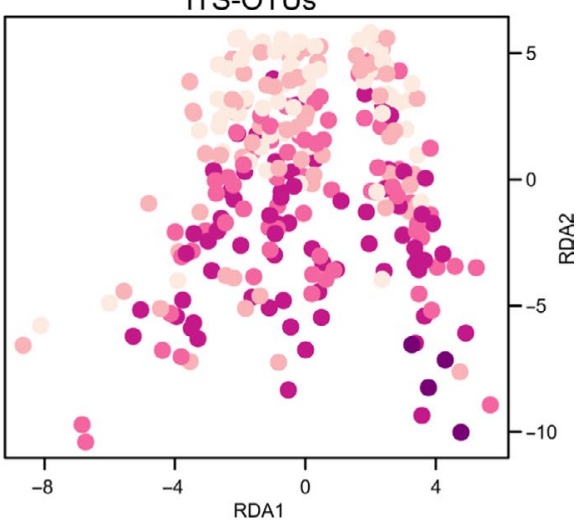

than compositions without grasses or legumes (Table 3). Particularly, plant communities containing grasses often had increased bacterial or fungal abundances (Figure S1). However, the presence of the two other plant functional groups, small or tall herbs, which combined species from different plant families and orders, only had weak effects on OTU abundances. Similarly, plant species richness did not strongly affect the pattern of OTU abundances.

For the fungal OTUs, we assessed the 'guild' and 'trophic mode' annotations (Table S3). Fungal OTUs significant for the plant species composition (plot after fitting spatial covariates), soil legacy or their interaction were depleted for pathotroph-saprotroph-symbiotroph and saprotroph fungi and enriched for pathotroph-symbiotroph fungi, respectively. Fungal OTUs affected by plant species composition $\times$ plant community history interactions were enriched for the guild endophytes. This guild was also more responsive than the average guild to plant species composition but not to soil legacy. Fungal OTUs significantly affected by plant species composition were enriched for plant pathogens and leaf saprotrophs, whereas soil-legacy treatment OTUs were enriched for animal pathogens, lichenized fungi and different saprotrophs (soil and wood saprotrophs).

Furthermore, contrasts for the above-ground biomass of every plant species within species compositions showed that the biomass of several grass and two legume species had significant effects on the abundance of large numbers of microbial OTUs, often in interaction with soil legacy, plant community history or both (Supporting Information 'Supporting Results. Effect of biomass proportions of each plant species' and Table S4). These were (in parentheses we indicate whether the species affected individual fungal, bacterial or both types of OTUs): the grasses Alopecurus pratensis (fungal OTUs), Arrhenatherum elatius (fungal OTUs), Bromus erectus (fungal OTUs), Dactylis glomerata (fungal OTUs), Festuca pratensis (fungal OTUs), Festuca rubra (bacterial and fungal OTUs), Poa trivialis (bacterial OTUs), Phleum pratense (fungal OTUs) and Trisetum flavescens (fungal OTUs) and the legumes Lathyrus pratensis (bacterial OTUs) and Medicago varia (bacterial and fungal OTUs).

\subsection{Effects of plant community history, soil legacy and plant species richness on soil chemistry and soil microbial biomass and activity}

Soil legacy contrasts and interactions with species composition (plot, after correction for spatial covariates) were significant for microbial $\mathrm{C}$ and $\mathrm{N}$, Olsen's $\mathrm{P}$ and $\mathrm{N}$ mineralization rates (Table S5). Old soils had higher microbial $\mathrm{C}$ and $\mathrm{N}$ and $\mathrm{N}$ mineralization rates but lower $\mathrm{P}$ than did new soil. The monoculture contrast and its interaction with soil legacy was significant for the levels of soil $\mathrm{N}$ mineralization rates and microbial $\mathrm{N}$, respectively. That is, plant mixtures had 
(a)
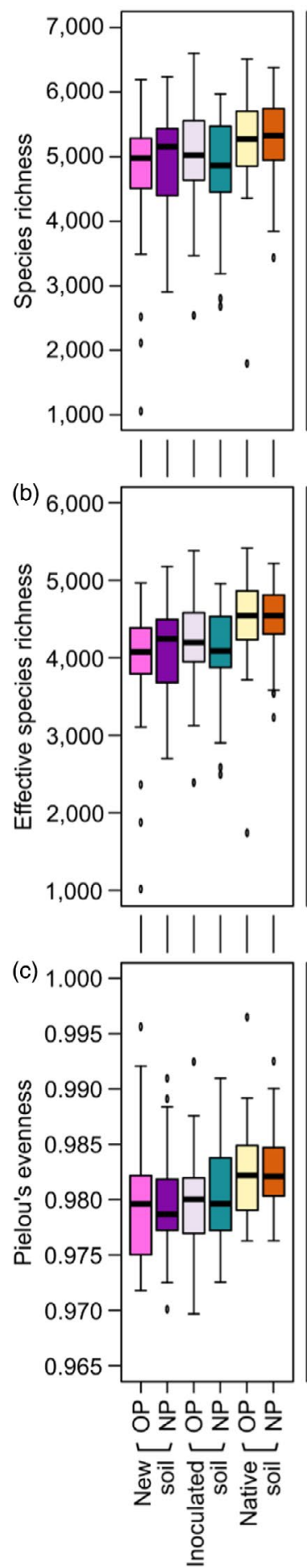

16S-OTUs
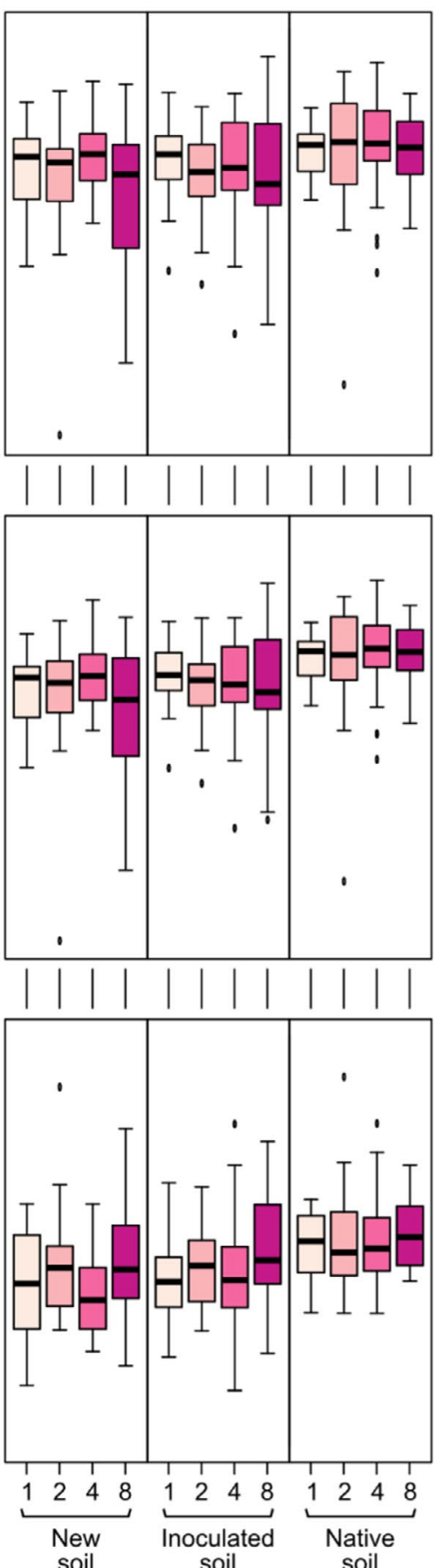

Plant species richness within soil legacies

ITS-OTUS
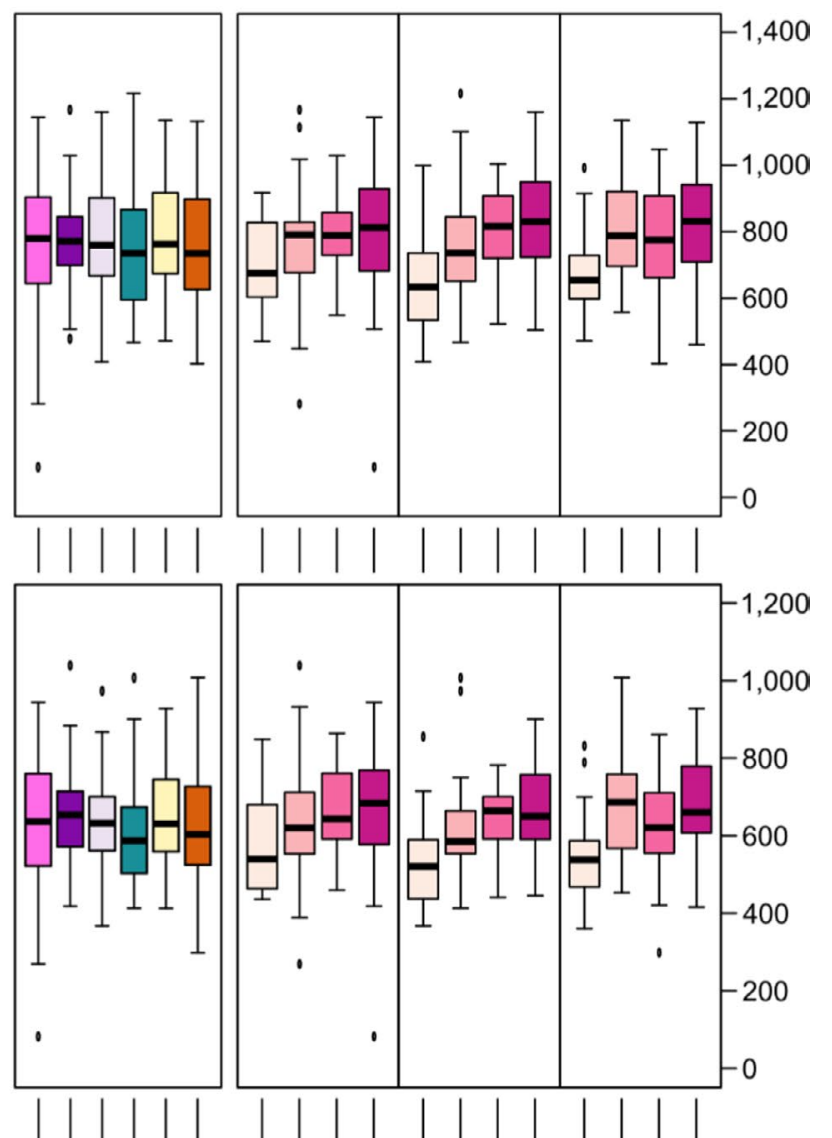

Soil legacy and plant community history across plant species richness
Soil legacy and plant community history across plant species richness

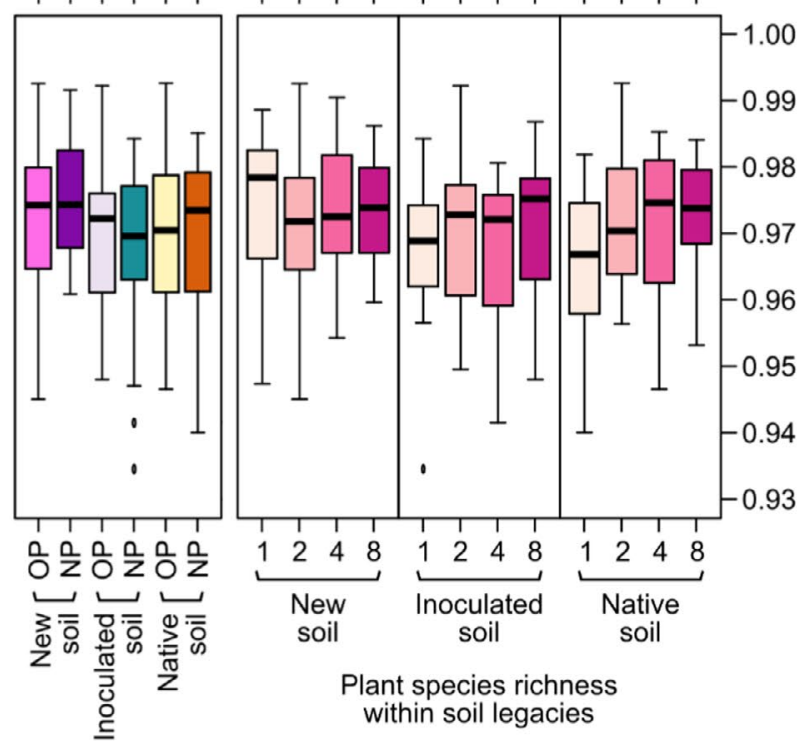

OP: Old plants NP: New plants

FIGURE 3 Effects of soil legacy, plant community history and plant species richness on soil bacterial (16S-OTUs, left side) and fungal (ITS-OTUs, right side) communities. (a) Microbial richness (number of OTUs with more than 0 reads), (b) microbial effective OTU richness and (c) Pielou's evenness. In a series of four panels, the left-most shows the biodiversity indices within each combination of plant community history and soil legacy (averaged across plant species richness). The three other panels show the indices within each combination of soil legacy and plant species richness (averaged across the two levels of plant community history). The ANOVA results are given in Table 1. Boxplots: the bottom and top of the boxes correspond to the lower and upper quartiles and the centerline marks the median. Whiskers extend to the lowest/highest values unless these values are lower/higher than the first/third quartile minus/plus 1.5 times the inner quartile range (IQR), which equals the third minus the first quartile 
TAB LE 3 The number of bacterial (A) and fungal (B) operational taxonomic units (OTUs) showing significant differential abundance (FDR $<0.01$ and \%-SS explained $>1 \%$ ) and the average percentage sum of squares (\%-SS) of either all OTUs or only the OTUs significant for the corresponding term. is monoculture: a contrast to compare plant monocultures with plant species mixtures, logSR: log2 of plant species richness, AGE: new soil compared with the two other soils, INO: inoculated compared with native soil, $\mathrm{CH}$ : plant community history. The term 'has Functional Group' corresponds to a factor testing for either presence of grasses/legumes/small herbs/tall herbs. For example, for the bacterial 16S-OTUs, 741 were significantly influenced by the presence of grasses and 46 were significantly influenced by the presence of legumes in plant communities. Interaction terms without significantly affected OTUs are not listed in the table, unless they are part of a contrast formation (AGE interactions in B)

\begin{tabular}{|c|c|c|c|}
\hline Source of variation & Number of significant OTUs & Average \%-SS (all OTUs) & $\begin{array}{l}\text { Average \%-SS } \\
\text { (significant OTUs) }\end{array}$ \\
\hline \multicolumn{4}{|l|}{ (A) Bacteria (16S) } \\
\hline is monoculture & 0 & 0.60 & - \\
\hline $\log (S R)$ & 0 & 0.53 & - \\
\hline Species composition (Plot) & 2,032 & 18.66 & 29.98 \\
\hline Soil new versus others (AGE) & 4,035 & 3.91 & 10.02 \\
\hline Soil inoculated versus native (INO) & 3,362 & 3.89 & 11.83 \\
\hline Plot $\times$ AGE & 238 & 13.50 & 17.00 \\
\hline Plot $\times$ INO & 118 & 13.72 & 18.56 \\
\hline Spatial variation & 156 & 4.73 & 18.56 \\
\hline is monoculture & 0 & 0.69 & - \\
\hline $\log (S R)$ & 0 & 0.70 & - \\
\hline Has functional group & $296 / 109 / 0 / 0$ & $2.50 / 1.69 / 0.77 / 0.68$ & $14.58 / 13.28 /-/-$ \\
\hline Species composition (Plot) & 1,173 & 22.60 & 35.79 \\
\hline Soil new versus others (AGE) & 389 & 1.69 & 9.74 \\
\hline Soil inoculated versus native (INO) & 224 & 1.12 & 8.81 \\
\hline is monoculture $\times \mathrm{AGE}$ & 0 & 0.41 & - \\
\hline Plot $\times$ INO & 471 & 13.44 & 20.11 \\
\hline Plant community history $(\mathrm{CH})$ & 0 & 0.27 & - \\
\hline Plot $\times \mathrm{CH}$ & 62 & 11.65 & 21.39 \\
\hline $\mathrm{AGE} \times \mathrm{CH}$ & 0 & 0.30 & - \\
\hline $\mathrm{INO} \times \mathrm{CH}$ & 10 & 0.25 & 0.01 \\
\hline $\log (\mathrm{SR}) \times \mathrm{SL} \times \mathrm{CH}$ & 1 & 0.58 & 9.06 \\
\hline
\end{tabular}

accumulated or retained more soil microbial $\mathrm{N}$ and higher mineralization rates than plant monocultures, especially in old soils. Plant communities containing grasses had higher soil $\mathrm{N}$ mineralization rates than plant communities not containing grasses.

The mediator analysis (Figure S2) showed that indirect effects of soil-legacy treatments on soil microbial communities often cancelled each other out. For example, there were positive indirect effects of soil legacy on bacterial and fungal evenness via microbial $\mathrm{C}$ but negative ones via microbial $\mathrm{N}$, that is, old soils had a positive effect on microbial $\mathrm{C}$, which then positively affected bacterial and fungal evenness. Old soils also had a positive effect on microbial $\mathrm{N}$, but this was negatively related to bacterial and fungal evenness. Total 


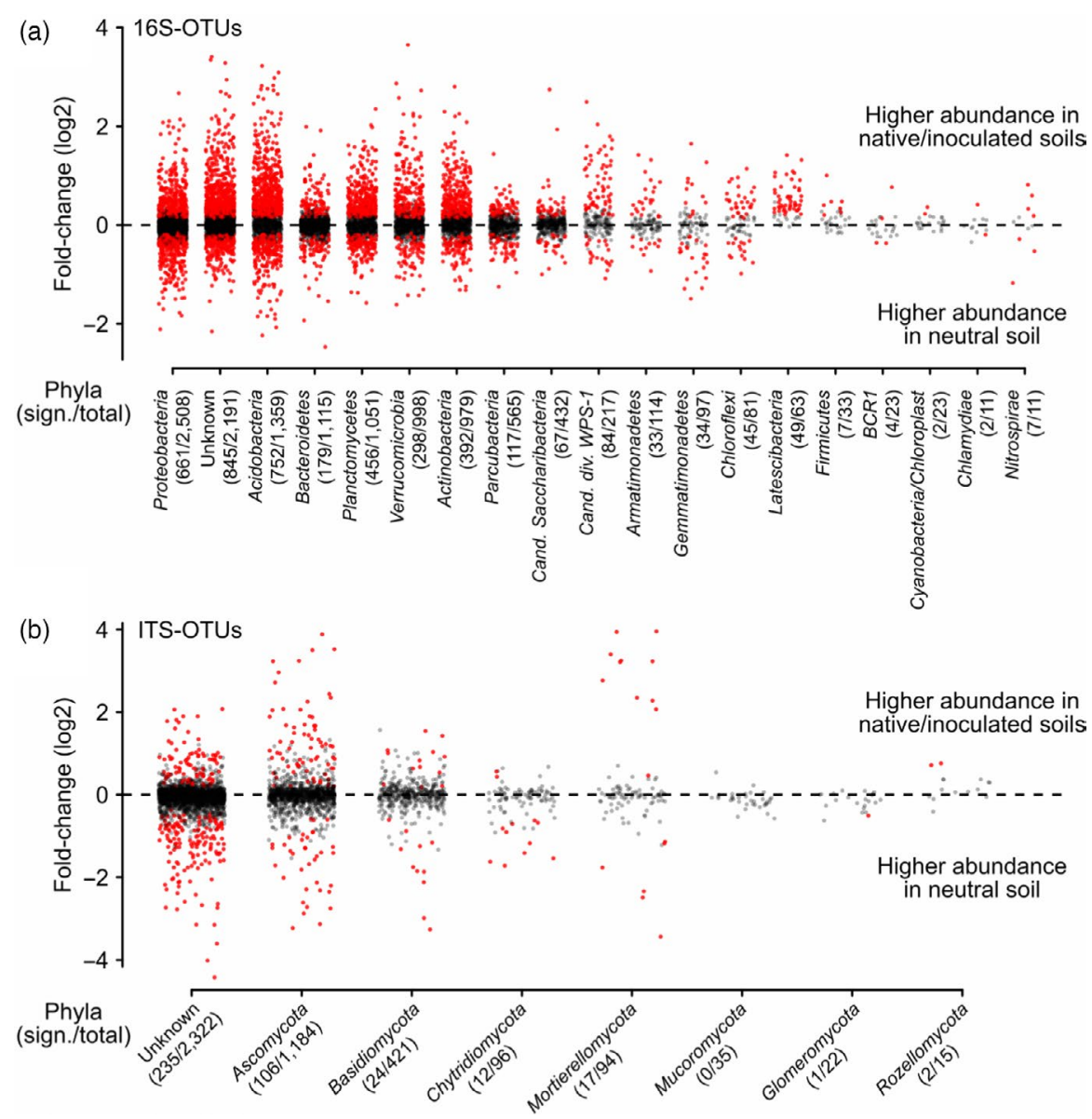

FIGURE 4 Difference in abundance of individual OTUs between native/ inoculated soils and new soil (log2 foldchanges, soil legacy contrast 'new vs. old (OLD)' in Table 3). (a) Bacterial OTU's, (b) fungal OUT's. Significant OTUs in red, others in black. Only phyla with at least 10 OTUs found in this study are shown. The number of significant and total number of OTUs are given in parentheses indirect effects of soil legacy were only observed for fungal richness and these were positive. No indirect effects of plant richness via soil variables on soil bacterial or fungal diversity could be observed (Figure S2). These results suggest that most of the treatment effects on soil microbial communities were direct effects of these treatments and not mediated by the measured soil covariates.

\section{4 | DISCUSSION}

\section{1 | Soil-legacy effects on soil microbial communities are stronger than plant community- history effects}

As expected, old soil had significantly higher bacterial richness and evenness than new soil. In contrast to bacterial evenness, old soi had lower fungal evenness. The different responses of bacterial and fungal diversity in our study are in line with previous findings in the Jena Experiment (e.g. Dassen et al., 2017; Lange et al., 2015) and may indicate different specificity of interactions between plants and soil bacteria and fungi or competition between taxa of bacteria and fungi (Bahram et al., 2018; Koorem et al., 2020). The fungal communities in old soils could have represented specialized subsets of fungal species particularly suited for the corresponding plant community (Semchenko et al., 2018; Sosa-Hernández et al., 2018). The co-assembly of plant and soil-microbial communities may be more strongly reflected in different taxonomic compositions of the soil community rather than their diversity (Figure 4). But even here, a greater proportion of bacterial (c. 30\%) than fungal OTUs $(<10 \%)$ were affected by soil legacy (Table 3 ).

Plant-soil microbial community assembly can be highly dynamic (Kardol et al., 2013; Lau \& Lennon, 2011, 2012; terHorst et al., 2014). Here, we found that 4 years of soil microbial community re-assembly under identical plant species compositions was not enough to remove the strong soil legacy effect that had developed under these same plant species compositions for 8 years before the experiment. The differences between soil treatments were even maintained through a severe natural flood at the field site in spring 2013 (van Moorsel et al., 2020); during which the plots were completely submerged by standing water. We found much faster adjustments of rhizosphere microbiomes in an associated experiment with the same soil legacy from the Jena Experiment (Schmid et al., 2019). Further away from plant roots soil microbial communities may change more slowly so that different results are apparent for bulk versus rhizosphere soil, with rhizosphere soils changing fast but with less longlasting legacy and changes in bulk soil being slower but becoming apparent as longer-lasting soil legacy effects.

In contrast to the strong effects of soil legacy on soil microbial communities, effects of plant community history were much weaker. This was unexpected because those same plant community history 
treatments led to significant plant evolutionary responses, including changes in plant-plant interactions (van Moorsel et al., 2018, 2020; Zuppinger-Dingley et al., 2014) and even altered plant-soil feedbacks (Hahl et al., 2020; Zuppinger-Dingley et al., 2016). These evolutionary changes in the plant communities may have been too small to become influential on the diversity and composition of soil microbial communities that may need more time to develop, or may have been too subtle to detect. Indeed, there were several subtle but significant effects of plant community history on bacterial and fungal taxa (Table 3), partly in interaction with soil legacy (on the abundance of specific fungal taxa, Table S3B) or in interaction with plant species composition (on bacterial richness, Table 1A).

The influence of an even longer plant community history on soil organismal communities is currently being studied in a longer-term new experiment at the Jena field site (Vogel et al., 2019). Effects of plant evolution on microbial communities so far are mainly being studied in model plants and for microbiomes directly associated with plant roots or leaves (Bergelson et al., 2019; Thiergart et al., 2020). We believe that the importance of the co-evolution between plants and their associated microbial communities in natural plant and soil communities is worthwhile investigating because they may both affect the maintenance of biodiversity in an ecosystem and the resulting effects of biodiversity on ecosystem functioning (van Moorsel et al., 2018, 2020).

\subsection{Plant diversity increases fungal diversity but otherwise has weak effects on soil microbial communities}

Plant species richness, especially the contrast between plant monocultures and mixtures, significantly increased fungal, but not bacterial richness. A previous study conducted on bulk soil also reported a marginally positive effect of plant species richness on fungal diversity in the Jena Experiment (Dassen et al., 2017). Contrary to our findings, others previously found that plant species richness increased bacterial diversity in the Jena Experiment (Lange et al., 2015), as well as in other grassland biodiversity experiments (Bartelt-Ryser et al., 2005; Stephan et al., 2000). Different experimental and sampling procedures may in part explain these different findings.

In terms of bacterial and fungal community composition, our samples tended to cluster along a plant species richness gradient from monocultures to 60 species-mixtures (Figure 1), indicating that plant diversity led to 'directed' microbial species turnover, as has been found in previous biodiversity experiments (Grüter et al., 2006; LeBlanc et al., 2015; Schlatter et al., 2015). However, another study with bulk soil from a grassland ecosystem in Texas found that fungal community composition was not influenced by plant diversity but rather by the addition of a single exotic plant species (Checinska Sielaff et al., 2018). Overall, these studies suggest bulk soil microbial communities are less strongly influenced by plant species richness than rhizosphere microbial communities. In addition, it may be that grassland soils perform differently compared with forest soils.
For example, tree species were shown to have a strong effect on soil fungal composition but not on soil fungal richness (Tedersoo et al., 2020).

In addition to the weak main effects of plant species richness on soil microbial communities, interactions with the soil legacy and plant community history treatments were also weak. Consequently, we could not support the hypothesis that in more diverse plant communities soil legacy and plant community history would more strongly influence soil microbial communities. Although such interactions would be expected based on general knowledge about the co-assembly of plant-soil communities (van der Putten et al., 2013; Schweitzer et al., 2014; Wagg et al., 2014; Wardle et al., 2004) our experimental approach might have been too crude to detect them. A limitation of our study was that for most of the detected OTUs we could not find specific matches with previously described microbial species (Brunel et al., 2020). We hope that we or others will reanalyse our data once this limitation has been overcome.

\subsection{Specific plant communities co-assemble with their specific soil communities}

Plots with different plant species compositions in our experiment varied in overall bacterial and fungal community diversity and structure. In part, this was due to the spatial position of the plots within the field site, which meant different abiotic soil conditions (i.e. sand, silt and clay content) depending on the plots' positions relative to the nearby river Saale (Dassen et al., 2017; Le Roux et al., 2013; Weisser et al., 2017). Still, large variation among plots remained after accounting for this spatial variation in the field site. Given that each plot had a unique community composition (except the four replicate 60 -species plots), this is evidence of plant community effects. However, we cannot exclude further plot-specific sources of variation that are not related to community composition.

Although the plant community compositions were only replicated within plots for the different soil-legacy and plant community history treatments, we could assess the importance of the presence or absence of specific plant functional groups or species with replicated plant communities between plots. Thus, variation among plots was partly due to the presence versus absence of grasses, which affected both soil bacterial and fungal communities, and to the presence versus absence of legumes, which here we found affected soil fungal communities. The presence of grasses in a community increased all fungal diversity indices and bacterial richness (Figure S1). In addition to the presence of grasses in general, the biomass contribution of several specific grass species to their plant communities also affected fungal and less often bacterial taxa, often in interaction with soil legacy, plant community history or both (Table S3). We note that plots with grasses had significantly higher soil microbial and nitrogen mineralization rates than plots without grasses, a finding also reported by Lama et al. (2020).

Effects of the presence of legumes on soil microbial communities, especially fungi, have been reported in previous studies (Dassen 
et al., 2017; König et al., 2010). Here, in addition to the presence of legumes it was the biomass contribution of two legume species (Lathyrus pratensis, Medicago varia) that affected a large number of microbial OTUs, either directly or (more often) in interaction with soil legacy, plant community history or both. This may be related to the potential of legumes to produce strigolactones as root exudates that promote the development of microbial symbionts (Peláez-Vico et al., 2016) or their $\mathrm{N}$-fixing nodules that render them P-limited rather than $\mathrm{N}$-limited, when compared with other plants (Vitousek \& Field, 1999). Compared with grasses and legumes, the taxonomically more diverse small or tall herb plant functional groups had no consistent effects on soil microbial communities. This is not surprising, because it is difficult to envision a mechanism that would link the abundance of an individual microbial OTU to the presence or absence of a diverse set of plant species. Instead, specific microbial OTUs may commonly associate with specific plant species, for which some candidates can be found in Table S4, but further analysis would be necessary once better annotations for our microbial OTUs become available.

Overall, our findings suggest that specific soil microbial communities not only associate with different plant species richness levels (see Figure 2) but additionally with specific plant species compositions within plant richness levels and that this process is influenced at least in part by soil legacy and plant community history. Some microbial OTUs may be typical for specific plant richness levels and others may be typical for specific plant species compositions (e.g. if they are specialized on specific plant species, Bezemer et al., 2010).

\subsection{Direct versus indirect effects of soil legacy and plant diversity on soil microbial communities}

We currently lack mechanistic explanations for the observed effects of plant community history, soil legacy and plant diversity and composition on soil microbial communities. As suggested by Dassen et al. (2017), plant species richness could increase fungal diversity through changes in soil properties such as increased root and litter availability in plots with more diverse plant communities. To assess the potential of soil biochemical variables to mediate indirect effects of our treatments, we used a mediator analysis (Burns \& Brandt, 2014). We found indirect effects of soil legacy via microbial $\mathrm{C}$ and $\mathrm{N}$ (both higher in old than in new soil) on almost all diversity indices of soil bacterial and fungal communities (Figure S2b). However, for bacterial indices the indirect effects cancelled out (two indices positive via $\mathrm{C}$ and negative via $\mathrm{N}$ mineralization); and for both bacterial and fungal indices direct effects remained. This suggests that soil legacy had created different soil microbial communities prior to the experiment and that soil covariates may have been a consequence rather than a cause of the different soil microbial communities.

The higher soil fungal richness with increasing plant diversity could not be explained by the measured soil biochemical variables, even though plots with plant mixtures had more soil microbial nitrogen and $\mathrm{N}$ mineralization rates than plots with plant monocultures, which was in line with previous studies showing a positive effect plant species richness on $\mathrm{N}$ mineralization rates (Rosenkranz et al., 2012; Zak et al., 2003). In contrast, Niklaus et al. (2007) did not find an effect of plant diversity on $\mathrm{N}$ mineralization rates. Here, the lack of indirect effects of plant diversity via soil biochemical variables suggests that treatment effects on soil microbial communities were not a correlate of soil environmental conditions.

\section{5 | CONCLUSIONS}

Using a long-term grassland biodiversity experiment as selection and community assembly experiment, we found that soil legacy, the diversity and composition of plant communities, and in a subtle way, plant community history shaped soil bacterial and fungal communities. Differences between soil microbial communities coming from the biodiversity experiment and soil microbial communities coming from newly assembled plant-soil communities persisted for at least 4 years under otherwise identical conditions. Our results show that long-term biodiversity loss in grassland ecosystems has lasting and often negative effects on soil microbial diversity and composition and downstream ecosystem processes and services. They further show that, during the plant-soil community assembly, microevolutionary and other sorting processes result in specific plant species compositions and functional groups being associated with specific bacterial and fungal community compositions, indicating a finetuning of species interactions that cannot be achieved within the short time of a few years.

\section{ACKNOWLEDGEMENTS}

We thank Daniel Trujillo for help with sampling, René Husi for conducting the PCR, Kentaro Shimizu and Misako Yamazaki for technical help, and the Genetic Diversity Centre (GDC) of the ETH Zurich for providing the facility to measure the concentration of the PCRcleanups. We thank Sigrid Dassen for her valuable and helpful comments on the manuscript and Leho Tedersoo, Benjamin Delory and Raúl Ochoa-Hueso for their constructive feedback in the peer review process. This study was supported by the Swiss National Science Foundation (grants number 147092 and 166457 to B. Schmid) and the University Research Priority Program Global Change and Biodiversity of the University of Zurich. The Jena Experiment is funded by The Deutsche Forschungsgemeinschaft (DFG, German Research Foundation, FOR1451). The authors declare no conflict of interest.

\section{AUTHORS' CONTRIBUTIONS}

S.J.v.M, T.H. and B.S. planned and designed the study; T.H. and S.J.v.M. carried out the field experiment; T.H. and S.J.v.M. performed the DNA extraction and sequencing preparation; E.D.L. collected soil samples and conducted soil analyses; C.W. and P.A.N. conducted soil analyses; P.A.N. processed the soil data; M.W.S. processed the sequencing data; M.W.S. performed all data analyses; The paper 
was written by S.J.v.M., M.W.S. and B.S. with substantial input from G.B.D.D. All authors contributed to the final version.

\section{PEER REVIEW}

The peer review history for this article is available at https://publons. com/publon/10.1111/1365-2745.13714.

\section{DATA AVAILABILITY STATEMENT}

The data presented in this paper are publicly available on Zenodo https://doi.org/10.5281/zenodo.4596692 (Schmid et al., 2020) and with the NCBI Sequence Read Archive (accession number PRJNA639013).

\section{ORCID}

Marc W. Schmid ID https://orcid.org/0000-0001-9554-5318 Sofia J. van Moorsel iD https://orcid.org/0000-0003-1947-8971 Gerlinde B. De Deyn (iD https://orcid.org/0000-0003-4823-6912 Cameron Wagg iD https://orcid.org/0000-0002-9738-6901 Pascal A. Niklaus (iD https://orcid.org/0000-0002-2360-1357 Bernhard Schmid iD https://orcid.org/0000-0002-8430-3214

\section{REFERENCES}

Aggarwal, C. C., Hinneburg, A., \& Keim, D. A. (2014). On the surprising behavior of distance metrics in high dimensional space. In E. Rosenberg, E. F. DeLong, S. Lory, E. Stackebrandt, \& F. Thompson (Eds.), Lecture notes in computer science (Vol. 1973; pp. 901-918). Springer.

Bahram, M., Hildebrand, F., Forslund, S. K., Anderson, J. L., Soudzilovskaia, N. A., Bodegom, P. M., Bengtsson-Palme, J., Anslan, S., Coelho, L. P., Harend, H., Huerta-Cepas, J., Medema, M. H., Maltz, M. R., Mundra, S., Olsson, P. A., Pent, M., Põlme, S., Sunagawa, S., Ryberg, M., ... Bork, P. (2018). Structure and function of the global topsoil microbiome. Nature, 560(7717), 233-237. https://doi.org/10.1038/s4158 6-018-0386-6

Bardgett, R. D., \& van der Putten, W. H. (2014). Belowground biodiversity and ecosystem functioning. Nature, 515(7528), 505-511. https:// doi.org/10.1038/nature13855

Bartelt-Ryser, J., Joshi, J., Schmid, B., Brandl, H., \& Balser, T. (2005). Soil feedbacks of plant diversity on soil microbial communities and subsequent plant growth. Perspectives in Plant Ecology, Evolution and Systematics, 7(1), 27-49. https://doi.org/10.1016/j.ppees.2004. 11.002

Bengtsson-Palme, J., Veldre, V., Ryberg, M., Hartmann, M., Branco, S., Wang, Z., Godhe, A., Bertrand, Y., De Wit, P., Sanchez, M., Ebersberger, I., Sanli, K., Desousa, F., Kristiansson, E., Abarenkov, J., Eriksson, K. M., \& Nilsson, R. H. (2013). ITSx: Improved software detection and extraction of ITS1 and ITS2 from ribosomal ITS sequences of fungi and other eukaryotes for use in environmental sequencing. Methods in Ecology and Evolution, 4, 914-919.

Benjamini, Y., \& Hochberg, Y. (1995). Controlling the False Discovery Rate: A practical and powerful approach to multiple testing. Journal of the Royal Statistical Society. Series B (Methodological), 57(1), 289300. https://doi.org/10.1111/j.2517-6161.1995.tb02031.x

Bergelson, J., Mittelstrass, J., \& Horton, M. W. (2019). Characterizing both bacteria and fungi improves understanding of the Arabidopsis root microbiome. Scientific Reports, 9(1), 24. https://doi.org/10.1038/ s41598-018-37208-z

Bezemer, T. M., Fountain, M. T., Barea, J. M., Christensen, S., Dekker, S. C., Duyts, H., van Hal, R., Harvey, J. A., Hedlund, K., Maraun, M., Mikola, J., Mladenov, A. G., Robin, C., de Ruiter, P. C., Scheu, S., Setälä, H., Šmilauer, P., \& van der Putten, W. H. (2010). Divergent composition but similar function of soil food webs of individual plants: Plant species and community effects. Ecology, 91(10), 3027-3036. https://doi. org/10.1890/09-2198.1

Bolger, A. M., Lohse, M., \& Usadel, B. (2014). Trimmomatic: A flexible trimmer for Illumina sequence data. Bioinformatics, 30(15), 21142120. https://doi.org/10.1093/bioinformatics/btu170

Brinkman, E. P., der Putten, W. H. V., Bakker, E.-J., \& Verhoeven, K. J. F. (2010). Plant-soil feedback: Experimental approaches, statistical analyses and ecological interpretations. Journal of Ecology, 98(5), 1063-1073. https://doi.org/10.1111/j.1365-2745.2010.01695.x

Brookes, P. C., Landman, A., Pruden, G., \& Jenkinson, D. S. (1985). Chloroform fumigation and the release of soil nitrogen: $A$ rapid direct extraction method to measure microbial biomass nitrogen in soil. Soil Biology \& Biochemistry, 17, 837-842. https://doi. org/10.1016/0038-0717(85)90144-0

Brunel, C., Pouteau, R., Dawson, W., Pester, M., Ramirez, K. S., \& van Kleunen, M. (2020). Towards unraveling macroecological patterns in rhizosphere microbiomes. Trends in Plant Science, 25(10), 1017-1029. https://doi.org/10.1016/j.tplants.2020.04.015

Burns, J. H., \& Brandt, A. J. (2014). Heterogeneity in plant-soil feedbacks and resident population dynamics affect mutual invasibility. Journal of Ecology, 102(4), 1048-1057. https://doi.org/10.1111/1365-2745. 12258

Checinska Sielaff, A., Upton, R. N., Hofmockel, K. S., Xu, X., Polley, H. W., \& Wilsey, B. J. (2018). Microbial community structure and functions differ between native and novel (exotic-dominated) grassland ecosystems in an 8-year experiment. Plant and Soil, 432(1-2), 359-372. https://doi.org/10.1007/s11104-018-3796-1

Cole, J. R., Wang, Q., Fish, J. A., Chai, B., McGarrell, D. M., Sun, Y., Brown, C. T., Porras-Alfaro, A., Kuske, C. R., \& Tiedje, J. M. (2014). Ribosomal Database Project: Data and tools for high throughput rRNA analysis. Nucleic Acids Research, 42, D633-D642. https://doi.org/10.1093/ nar/gkt1244

Dassen, S., Cortois, R., Martens, H., de Hollander, M., Kowalchuk, G. A., van der Putten, W. H., \& De Deyn, G. B. (2017). Differential responses of soil bacteria, fungi, archaea and protists to plant species richness and plant functional group identity. Molecular Ecology. https://doi.org/10.1111/mec.14175

Dudenhöffer, J.-H., Ebeling, A., Klein, A.-M., \& Wagg, C. (2018). Beyond biomass: Soil feedbacks are transient over plant life stages and alter fitness. Journal of Ecology, 106(1), 230-241. https://doi. org/10.1111/1365-2745.12870

Edgar, R. C. (2013). UPARSE: Highly accurate OTU sequences from microbial amplicon reads. Nature Methods, 10(10), 996-998. https://doi. org/10.1038/nmeth.2604

Edgar, R. C. (2016). SINTAX: A simple non-Bayesian taxonomy classifier for 16S and ITS sequences. Biorxiv. https://doi.org/10.1101/074161

Gravel, D., Bell, T., Barbera, C., Bouvier, T., Pommier, T., Venail, P., \& Mouquet, N. (2011). Experimental niche evolution alters the strength of the diversity-productivity relationship. Nature, 469(7328), 89-92. https://doi.org/10.1038/nature09592

Grüter, D., Schmid, B., \& Brandl, H. (2006). Influence of plant diversity and elevated atmospheric carbon dioxide levels on belowground bacterial diversity. BMC Microbiology, 6(1), 68. https://doi. org/10.1186/1471-2180-6-68

Hahl, T., van Moorsel, S. J., Schmid, M. W., Zuppinger-Dingley, D., Schmid, B., \& Wagg, C. (2020). Plant responses to diversity-driven selection and associated rhizosphere microbial communities. Functional Ecology, 34(3), 707-722. https://doi.org/10.1111/1365-2435.13511

Haines-Young, R., \& Potschin, M. (2010). The links between biodiversity, ecosystem services and human well-being. In D. G. Raffaelli, \& C. L. J. Frid (Eds.), Ecosystem ecology (pp. 110-139). Cambridge University Press. https://doi.org/10.1017/CBO9780511750458.007

Herlemann, D. P. R., Labrenz, M., Juergens, K., Bertilsson, S., Waniek, J. J., \& Anderrson, A. F. (2011). Transition in bacterial communities 
along the $2000 \mathrm{~km}$ salinity gradient of the Baltic Sea. ISME Journal, 5, 1571-1579. https://doi.org/10.1038/ismej.2011.41

Kardol, P., Cornips, N. J., van Kempen, M. M. L., Bakx-Schotman, J. M. T., \& van der Putten, W. H. (2007). Microbe-mediated plant-soil feedback causes historical contingency effects in plant community assembly. Ecological Monographs, 77(2), 147-162. https://doi. org/10.1890/06-0502

Kardol, P., De Deyn, G. B., Laliberté, E., Mariotte, P., \& Hawkes, C. V. (2013). Biotic plant-soil feedbacks across temporal scales. Journal of Ecology, 101(2), 309-315. https://doi.org/10.1111/1365-2745.12046

Keeney, D. R. (1982). Nitrogen-availability indices. In A. L. Page (Ed.), Methods of soil analysis, part 2. Chemical and microbiological properties (2nd ed., Vol. 9, pp. 711-733). American Society of Agronomy, Soil Science Society of America. https://doi.org/10.2134/agronmonog r9.2.2ed.c35

Klironomos, J. N. (2002). Feedback with soil biota contributes to plant rarity and invasiveness in communities. Nature, 417(6884), 67-70. https://doi.org/10.1038/417067a

König, S., Wubet, T., Dormann, C. F., Hempel, S., Renker, C., \& Buscot, F. (2010). TaqMan real-time PCR assays to assess arbuscular mycorrhizal responses to field manipulation of grassland biodiversity: Effects of soil characteristics, plant species richness, and functional traits. Applied and Environmental Microbiology, 76(12), 3765-3775. https:// doi.org/10.1128/AEM.02951-09

Koorem, K., Snoek, B. L., Bloem, J., Geisen, S., Kostenko, O., Manrubia, M., Ramirez, K. S., Weser, C., Wilschut, R. A., \& van der Putten, W. H. (2020). Community-level interactions between plants and soil biota during range expansion. Journal of Ecology, 108(5), 1860-1873. https://doi.org/10.1111/1365-2745.13409

Lama, S., Kuhn, T., Lehmann, M. F., Müller, C., Gonzalez, O., Eisenhauer, N., Lange, M., Scheu, S., Oelmann, Y., \& Wilcke, W. (2020). The biodiversity - $\mathrm{N}$ cycle relationship: A $15 \mathrm{~N}$ tracer experiment with soil from plant mixtures of varying diversity to model $\mathrm{N}$ pool sizes and transformation rates. Biology and Fertility of Soils, https://doi.org/10.1007/ s00374-020-01480-x

Lange, M., Eisenhauer, N., Sierra, C. A., Bessler, H., Engels, C., Griffiths, R. I., Mellado-Vázquez, P. G., Malik, A. A., Roy, J., Scheu, S., Steinbeiss, S., Thomson, B. C., Trumbore, S. E., \& Gleixner, G. (2015). Plant diversity increases soil microbial activity and soil carbon storage. Nature Communications, 6(1). https://doi.org/10.1038/ncomms7707

Lau, J. A., \& Lennon, J. T. (2011). Evolutionary ecology of plantmicrobe interactions: Soil microbial structure alters selection on plant traits. New Phytologist, 192(1), 215-224. https://doi. org/10.1111/j.1469-8137.2011.03790.x

Lau, J. A., \& Lennon, J. T. (2012). Rapid responses of soil microorganisms improve plant fitness in novel environments. Proceedings of the National Academy of Sciences of the United States of America, 109(35), 14058-14062. https://doi.org/10.1073/pnas.1202319109

Le Roux, X., Schmid, B., Poly, F., Barnard, R. L., Niklaus, P. A., Guillaumaud, N., Habekost, M., Oelman, Y., Philippot, L., Falcao Salles, J., Schloter, M., Steinbeiss, S., \& Weigelt, A. (2013). Soil environmental conditions and microbial build-up mediate the effect of plant diversity on soil nitrifying and denitrifying enzyme activities in temperate grasslands. PLoS ONE, 8, e61069. https://doi.org/10.1371/journal.pone.0061069

LeBlanc, N., Kinkel, L. L., \& Kistler, H. C. (2015). Soil fungal communities respond to grassland plant community richness and soil edaphics. Microbial Ecology, 70(1), 188-195. https://doi.org/10.1007/s0024 8-014-0531-1

Lozupone, C., Lladser, M. E., Knights, D., Stombaugh, J., \& Knight, R. (2011). UniFrac: An effective distance metric for microbial community comparison. ISME Journal, 5, 169-172. https://doi.org/10.1038/ ismej. 2010.133

McMurdie, P. J., \& Holmes, S. (2014). Waste not, want not: Why rarefying microbiome data is inadmissible. PLoS Computational Biology, 10(4), e1003531. https://doi.org/10.1371/journal.pcbi.1003531
McNamara, N., Black, H. I. J., Beresford, N., \& Parekh, N. R. (2003) Effect of acute gamma irradiation on chemical, physical and biological properties of soils. Applied Soil Ecology, 24, 117-132. https://doi. org/10.1016/S0929-1393(03)00073-8

Nguyen, N. H., Song, Z., Bates, S. T., Branco, S., Tedersoo, L., Menke, J., Schilling, J. S., \& Kennedy, P. G. (2016). FUNGuild: An open annotation tool for parsing fungal community datasets by ecological guild. Fungal Ecology, 20, 241-248. https://doi.org/10.1016/j. funeco.2015.06.006

Niklaus, P. A., Alphei, J., Kampichler, C., Kandeler, E., Körner, C., Tscherko, D., \& Wohlfender, M. (2007). Interactive effects of plant species diversity and elevated $\mathrm{CO}_{2}$ on soil biota and nutrient cycling. Ecology, 88(12), 3153-3163. https://doi.org/10.1890/06-2100.1

Nilsson, R. H., Larsson, K.-H., Taylor, A. F. S., Bengtsson-Palme, J., Jeppesen, T. S., Schigel, D., Kennedy, P., Picard, K., Glöckner, F. O., Tedersoo, L., Saar, I., Kõljalg, U., \& Abarenkov, K. (2019). The UNITE database for molecular identification of fungi: Handling dark taxa and parallel taxonomic classifications. Nucleic Acids Research, 47, D259-D264. https://doi.org/10.1093/nar/gky1022

Oksanen, J., Blanchet, F. G., Friendly, M., Kindt, R., \& Legendre, P., McGlinn, D., Minchin, P. R., O'Hara, R. B., Simpson, G. L., Solymos, P., Stevens, M. H. H., Szoecs, E., \& Wagner, H. (2017). Vegan: Community ecology package. https://CRAN.R-project.org/package=vegan

Olsen, S. R., Cole, C. V., Watanabe, F. S., \& Dean, L. A. (1954). Estimation of available phosphorus in soils by extraction with sodium bicarbonate. U.S. Government Printing Office.

Peláez-Vico, M. A., Bernabéu-Roda, L., Kohlen, W., Soto, M. J., \& LópezRáez, J. A. (2016). Strigolactones in the Rhizobium-legume symbiosis: Stimulatory effect on bacterial surface motility and down-regulation of their levels in nodulated plants. Plant Science: An International Journal of Experimental Plant Biology, 245, 119-127. https://doi. org/10.1016/j.plantsci.2016.01.012

Pertea, G. (2015). fatrim: V0.9.4 release. https://doi.org/10.5281/ zenodo. 20552

Petermann, J. S., Fergus, A. J., Turnbull, L. A., \& Schmid, B. (2008). Janzen-Connell effects are widespread and strong enough to maintain diversity in grasslands. Ecology, 89(9), 2399-2406. https://doi. org/10.1890/07-2056.1

R Development Core Team. (2017). R: A language and environment for statistical computing. R Foundation for Statistical Computing. http:// www.R-project.org

Roscher, C., Schumacher, J., Baade, J., Wilcke, W., Gleixner, G., Weisser, W. W., Schmid, B., \& Schulze, E.-D. (2004). The role of biodiversity for element cycling and trophic interactions: An experimental approach in a grassland community. Basic and Applied Ecology, 5(2), 107-121. https://doi.org/10.1078/1439-1791-00216

Rosenkranz, S., Wilcke, W., Eisenhauer, N., \& Oelmann, Y. (2012). Net ammonification as influenced by plant diversity in experimental grasslands. Soil Biology and Biochemistry, 48, 78-87. https://doi. org/10.1016/j.soilbio.2012.01.008

Rosseel, Y. (2012). lavaan: An R package for structural equation modeling. Journal of Statistical Software, 48(2). https://doi.org/10.18637/ jss.v048.i02

Schlatter, D. C., Bakker, M. G., Bradeen, J. M., \& Kinkel, L. L. (2015). Plant community richness and microbial interactions structure bacterial communities in soil. Ecology, 96(1), 134-142. https://doi. org/10.1890/13-1648.1

Schmid, B., Baruffol, M., Wang, Z., \& Niklaus, P. A. (2017). A guide to analyzing biodiversity experiments. Journal of Plant Ecology, 10, 91-110. https://doi.org/10.1093/jpe/rtw107

Schmid, B., Hector, A., Huston, M. A., Inchausti, P., Nijs, I., Leadley, P. W., \& Tilman, D. (2002). The design analysis of biodiversity experiments. In M. Loreau, S. Naeem, \& P. Inchausti (Eds.), Biodiversity and ecosystem functioning, synthesis and perspectives (pp. 61-75). Oxford University Press Inc. 
Schmid, M. W., Hahl, T., van Moorsel, S. J., Wagg, C., De Deyn, G. B., \& Schmid, B. (2019). Feedbacks of plant identity and diversity on the diversity and community composition of rhizosphere microbiomes from a long-term biodiversity experiment. Molecular Ecology, 28(4), 863-878. https://doi.org/10.1111/mec.14987

Schmid, M. W., von Moorsel, S. J., Hahl, T., De Luca, E., Wagg, C., Niklaus, P. A., \& Schmid, B. (2020). Effects of plant diversity and community age on soil microbial communities [Dataset]. Zenodo, https://doi. org/10.5281/zenodo.4596692

Schweitzer, J. A., Juric, I., van de Voorde, T. F. J., Clay, K., van der Putten, W. H., \& Bailey, J. K. (2014). Are there evolutionary consequences of plant-soil feedbacks along soil gradients? Functional Ecology, 28(1), 55-64. https://doi.org/10.1111/1365-2435.12201

Semchenko, M., Leff, J. W., Lozano, Y. M., Saar, S., Davison, J., Wilkinson, A., Jackson, B. G., Pritchard, W. J., De Long, J. R., Oakley, S., Mason, K. E., Ostle, N. J., Baggs, E. M., Johnson, D., Fierer, N., \& Bardgett, R. D. (2018). Fungal diversity regulates plant-soil feedbacks in temperate grassland. Science Advances, 4(11), eaau4578. https://doi. org/10.1126/sciadv.aau4578

Sosa-Hernández, M. A., Roy, J., Hempel, S., \& Rillig, M. C. (2018). Evidence for subsoil specialization in arbuscular mycorrhizal fungi. Frontiers in Ecology and Evolution, 6, 67. https://doi.org/10.3389/ fevo.2018.00067

Stephan, A., Meyer, A. H., \& Schmid, B. (2000). Plant diversity affects culturable soil bacteria in experimental grassland communities. Journal of Ecology, 88(6), 988-998. https://doi.org/10.1046/j.1365-2745.2000. 00510.x

Tedersoo, L., Anslan, S., Bahram, M., Drenkhan, R., Pritsch, K., Buegger, F., Padari, A., Hagh-Doust, N., Mikryukov, V., Gohar, D., Amiri, R., Hiiesalu, I., Lutter, R., Rosenvald, R., Rähn, E., Adamson, K., Drenkhan, T., Tullus, H., Jürimaa, K., ... Abarenkov, K. (2020). Regional-scale indepth analysis of soil fungal diversity reveals strong $\mathrm{pH}$ and plant species effects in Northern Europe. Frontiers in Microbiology, 11, 1953. https://doi.org/10.3389/fmicb.2020.01953

terHorst, C. P., Lennon, J. T., \& Lau, J. A. (2014). The relative importance of rapid evolution for plant-microbe interactions depends on ecological context. Proceedings of the Royal Society B: Biological Sciences, 281(1785), 20140028. https://doi.org/10.1098/rspb.2014.0028

Thiergart, T., Durán, P., Ellis, T., Vannier, N., Garrido-Oter, R., Kemen, E., Roux, F., Alonso-Blanco, C., Ågren, J., Schulze-Lefert, P., \& Hacquard, S. (2020). Root microbiota assembly and adaptive differentiation among European Arabidopsis populations. Nature Ecology \& Evolution, 4(1), 122-131. https://doi.org/10.1038/s41559-019-1063-3

Toju, H., Tanabe, A. S., Yamamoto, S., \& Sato, H. (2012). High-coverage ITS primers for the DNA-based identification of Ascomycetes and Basidiomycetes in environmental samples. PLoS ONE, 7, e40863. https://doi.org/10.1371/journal.pone.0040863

van der Heijden, M. G. A., Bardgett, R. D., \& van Straalen, N. M. (2008). The unseen majority: Soil microbes as drivers of plant diversity and productivity in terrestrial ecosystems. Ecology Letters, 11(3), 296310. https://doi.org/10.1111/j.1461-0248.2007.01139.x

van der Putten, W. H., Bardgett, R. D., Bever, J. D., Bezemer, T. M., Casper, B. B., Fukami, T., Kardol, P., Klironomos, J. N., Kulmatiski, A., Schweitzer, J. A., Suding, K. N., Van de Voorde, T. F. J., \& Wardle, D. A. (2013). Plant-soil feedbacks: The past, the present and future challenges. Journal of Ecology, 101(2), 265-276. https://doi. org/10.1111/1365-2745.12054

van Moorsel, S. J., Hahl, T., Petchey, O. L., Ebeling, A., Eisenhauer, N., Schmid, B., \& Wagg, C. (2020). Co-occurrence history increases ecosystem stability and resilience in experimental plant communities. Ecology, e03205. https://doi.org/10.1002/ecy.3205

van Moorsel, S. J., Hahl, T., Wagg, C., De Deyn, G. B., Flynn, D. F. B., Zuppinger-Dingley, D., \& Schmid, B. (2018). Community evolution increases plant productivity at low diversity. Ecology Letters, 21, 128137. https://doi.org/10.1111/ele.12879
Vance, E. D., Brookes, P. C., \& Jenkinson, D. S. (1987). An extraction method for measuring soil microbial biomass C. Soil Biology \& Biochemistry, 19 , 703-707. https://doi.org/10.1016/0038-0717(87)90052-6

Vitousek, P. M., \& Field, C. B. (1999). Ecosystem constraints to symbiotic nitrogen fixers: A simple model and its implications. Biogeochemistry, 46(1-3), 179-202. https://doi.org/10.1007/BF01007579

Vogel, A., Ebeling, A., Gleixner, G., Roscher, C., Scheu, S., Ciobanu, M., Koller-France, E., Lange, M., Lochner, A., Meyer, S. T., Oelmann, Y., Wilcke, W., Schmid, B., \& Eisenhauer, N. (2019). A new experimental approach to test why biodiversity effects strengthen as ecosystems age. Advances in ecological research. Academic Press. https://doi. org/10.1016/bs.aecr.2019.06.006

Wagg, C., Boller, B., Schneider, S., Widmer, F., \& van der Heijden, M. G. A. (2014). Intraspecific and intergenerational differences in plant-soil feedbacks. Oikos, 124(8), 994-1004. https://doi.org/10.1111/oik. 01743

Wagg, C., Schlaeppi, K., Banerjee, S., Kuramae, E. E., \& van der Heijden, M. G. A. (2019). Fungal-bacterial diversity and microbiome complexity predict ecosystem functioning. Nature Communications, 10(1), https://doi.org/10.1038/s41467-019-12798-y

Wardle, D. A., Bardgett, R. D., Klironomos, J. N., Setälä, H., Van der Putten, W. H., \& Wall, D. H. (2004). Ecological linkages between aboveground and belowground biota. Science, 304(5677), 1629-1633. https://doi.org/10.1126/science.1094875

Watanabe, F. S., \& Olsen, S. R. (1965). Test of an ascorbic acid method for determining phosphorus in water and $\mathrm{NaHCO}_{3}$ extracts from soil. Soil Science Society of America Journal, 29(6), 677-678. https://doi. org/10.2136/sssaj1965.03615995002900060025x

Weisser, W. W., Roscher, C., Meyer, S. T., Ebeling, A., Luo, G., Allan, E., Beßler, H., Barnard, R. L., Buchmann, N., Buscot, F., Engels, C., Fischer, C., Fischer, M., Gessler, A., Gleixner, G., Halle, S., Hildebrandt, A., Hillebrand, H., de Kroon, H., ... Eisenhauer, N. (2017). Biodiversity effects on ecosystem functioning in a 15-year grassland experiment: Patterns, mechanisms, and open questions. Basic and Applied Ecology, 23, 1-73. https://doi.org/10.1016/j.baae.2017.06.002

Zak, D. R., Holmes, W. E., White, D. C., Peacock, A. D., \& Tilman, D. (2003). Plant diversity, soil microbial communities, and ecosystem function: Are there any links? Ecology, 84(8), 2042-2050. https://doi. org/10.1890/02-0433

Zuppinger-Dingley, D., Flynn, D. F. B., De Deyn, G. B., Petermann, J. S., \& Schmid, B. (2016). Plant selection and soil legacy enhance longterm biodiversity effects. Ecology, 97(4), 918-928. https://doi. org/10.1890/15-0599.1

Zuppinger-Dingley, D., Schmid, B., Petermann, J. S., Yadav, V., De Deyn, G. B., \& Flynn, D. F. B. (2014). Selection for niche differentiation in plant communities increases biodiversity effects. Nature, 515(7525), 108-111. https://doi.org/10.1038/nature13869

\section{SUPPORTING INFORMATION}

Additional supporting information may be found online in the Supporting Information section.

How to cite this article: Schmid, M. W., van Moorsel, S. J., Hahl, T., De Luca, E., De Deyn, G. B., Wagg, C., Niklaus, P. A., \& Schmid, B. (2021). Effects of plant community history, soil legacy and plant diversity on soil microbial communities. Journal of Ecology, 109, 3007-3023. https://doi. org/10.1111/1365-2745.13714 